\title{
Established Urban Research Traditions and the Platform for Space Syntax
}

\section{Contents}

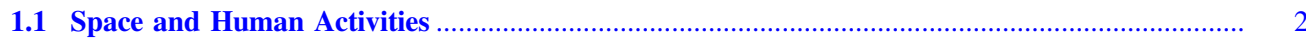

1.2 Established Traditions for the Physical Form of Cities....................................................... 5

1.2.1 Urban Morphology Tradition ........................................................................................ 5

1.2.2 Place Phenomenological Tradition ................................................................................... 11

1.2.3 Urban (Street) Network Tradition ..................................................................................... 15

1.3 The Platform for Space Syntax: Definitions of Urban Space ……........................................ 20

1.3.1 Intrinsic Properties of Urban Space ......................................................................... 21

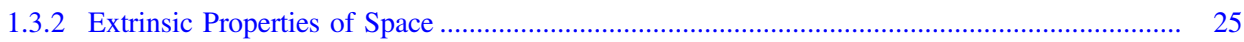

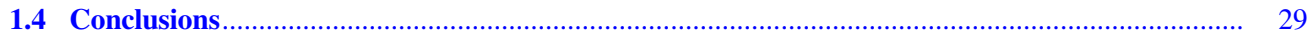

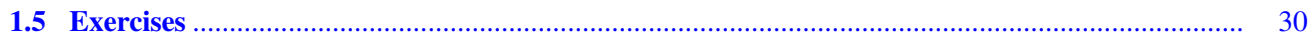

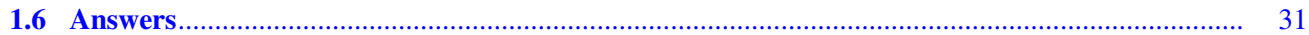

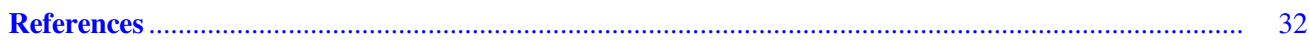

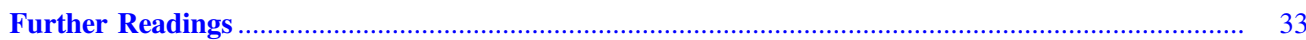

\section{Abstract}

This chapter provides an overview of established research traditions in the analysis of physical elements of the built environment. Herein, we address the morphological, place phenomenological, and urban network traditions. Following this, a synopsis about spatial elements applied to these traditions, including space syntax, is given. Furthermore, in this chapter, we explain the differences between extrinsic and intrinsic properties of space and clarify the typology concepts of the built form. Finally, we introduce the basic spatial elements used in space syntax and the simplest spatial structures that cities can have. Exercises are provided at the end of this chapter.

\section{Keywords}

Built environment - Human activities - Spatial elements $\bullet$ Extrinsic and intrinsic properties of space

\section{Key Concepts}

Urban morphology analyses • Place phenomenology analyses • Urban network analyses 


\section{Learning Objectives:}

After studying this chapter, you will

- have an understanding of the relationship between urban space and human activities and their mutual influence, the socio-spatial relationship;

- have knowledge about the three research traditions with regards to the physical aspects of built environments, namely urban morphological tradition, place phenomenological tradition, and urban network tradition;

- be able to conduct simple analyses based on the Spacematrix, mixed-use index (MXI), street functions, street profiles, and Kevin Lynch's image of the city methods;

- be able to reflect on the differences between extrinsic and intrinsic properties connected to space syntax.

\subsection{Space and Human Activities}

Every city and neighbourhood is unique and differs from all others. There are no two cities or neighbourhoods that are alike. Despite their diversity, they also share similarities. Some cities have similar building types and architectural styles, while others embrace similar street patterns, types of transportation hubs, or types of bridges. But how can we compare cities and their neighbourhoods with each other? What kind of spatial tools do we have for comparing cities?

Human societies are spatial phenomena - they occupy regions of the Earth's surface, and within and between these regions material resources move, people encounter each other, and information is transmitted (Hillier and Hanson 1984, p. 26). Human activities influence the shapes of cities, their urban patterns, the order of their physical elements, and their meanings. Politically accepted plans, building regulations, and the way human beings spatially conduct their social and economic activities have an impact on how urban areas are built. Thus, cultures shape cities over time.

Vice versa, the urban form influences human activities. For example, with regard to active land use and location choice, shop owners will always try to optimise the location of their shops to reach the greatest number of customers. If an optimal location is affected by a significant change of the urban area, they will relocate their businesses (van Nes 2002, p. 300). Another example is that of an urban area where pedestrians feel unsafe due to high criminality. In many post-war urban areas, crime and vandalism started to become a problem just a few years after such areas were built (van Wegen and van der Voort 1991). These were unpredicted effects because the original planning intervention was to create quiet and harmonious dwelling areas. Incidents like these naturally are a combination of an urban area's spatial structure and the social composition of its inhabitants (Shu 2000). All these examples show that there is a strong relationship between the built environment's spatial arrangement and human activities.

The spatial arrangement of the built environment has its own laws (Hillier 1996). Therefore, tools are needed to reveal the underlying logic of the relationship between the physical objects of the built environment. Comprehending how physical objects are placed and related to each other in cities can contribute to the understanding of integrated, segregated, connected, or disconnected spaces and urban areas in cities. Learning about the 'hidden laws' and how the socio-spatial relationships can be calculated provides us with knowledge on how the built form functions as a framework for creating contact or avoidance for its users. Often, inherent rules for how spaces are organised are taken for granted in the way humans organise their lives. Thus, there is little awareness of these underlying logics.

Analysing and comparing different cities and their urban areas with one another require the analysis of spatial parameters separately from social parameters. In a subsequent step, the numerical results from the spatial analysis can be correlated with socio-economic data. Indeed, spatial analysis and modelling always deal with the abstraction and thus the simplification of reality. However, this two-step procedure of first conducting a spatial analysis and second correlating the results with socio-economic data provides an understanding of how human activities shape cities and how the shape of cities influences human activities. 
In order to explain how spatial relationships affect social relationships, we use the spatial setup of a dwelling as an example. Figure 1.1 depicts the plan of a Norwegian bungalow from the 1970s for a family of two adults and two children. The parents' bedroom is adjacent to the kitchen, and the children's bedrooms are adjacent to the TV room.

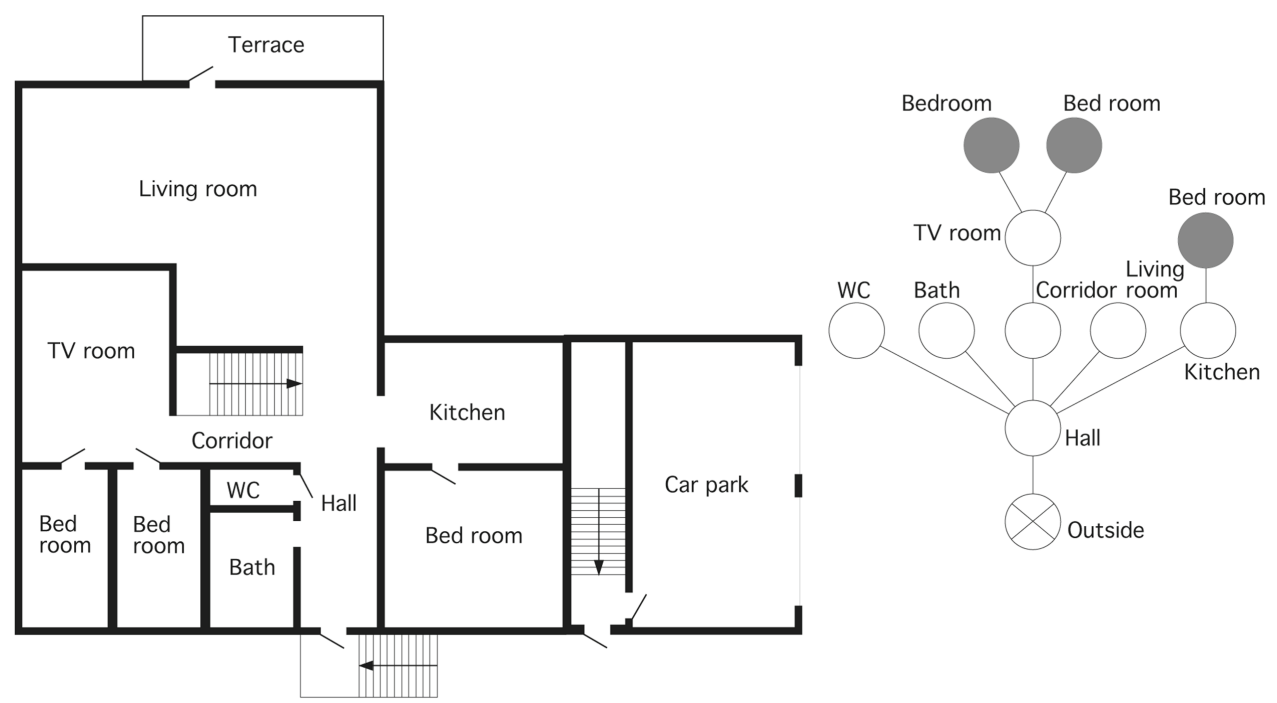

Fig. 1.1 Floor plan of a Norwegian bungalow (left) and a justified graph (right) representing the spatial relationships

A justified graph (Fig. 1.1, right) illustrates the spatial relationships or connections between the bungalow's various rooms. Each room is represented by a circle (= node) while connections, herein doors, between the rooms are represented by lines (= edges). The graph shows how the bungalow is experienced starting from the main entrance, represented as a circle with a cross through it (= root node). Every time a new room is entered, or there is a direction change within a room, a so-called topological step is taken. Because we only depict the spatial relationships, the geometries and sizes of the rooms are not of interest. In order to generate a justified graph, only the spatial configurational relationship is taken into consideration when studying spatial patterns or the spatial configuration.

The justified graph is used in graph theory, which is the study of mathematic structures between objects. The objects, which are rooms or spaces in our case, are represented as nodes. The connections between these nodes are represented as edges. The justified graph in Fig. 1.1 displays in a uniform, but abstract, way the spatial configuration of a bungalow. This architectural example allows us to explain in a simple way the relationship between space and human activities. In Chap. 2. we will show how this graph can be used to calculate the relations between spatial elements for cities.

One of the findings of the justified graph for the Norwegian bungalow is that all bedrooms are topologically farthest away from the main entrance. Thus, they are located 'topologically deep'. Moreover, these bedrooms are 'dead-end' spaces meaning that they cannot be passed through to enter other rooms. These kinds of spaces can be meaningful where privacy is highly appreciated. Another example of a dead-end space is the bathroom. Also, here privacy is the main characteristic.

To build a narrative of spatial change, the bungalow was later sold to a young family with one toddler and was refurbished. Two walls were torn down, one to merge the bath and a bedroom, and another to merge the kitchen and the bedroom. This was to have a large kitchen and bathroom. The former terrace was converted to a winter garden serving as an extension to the bungalow. The narrative behind these changes are, for example, activities related to more space for a whirlpool in the bathroom and only one additional bedroom is necessary because the new owners have only one child. However, the direct access from the master bedroom to the child's bedroom might compromise the privacy of the parents at a later stage when the child is an adolescent. 


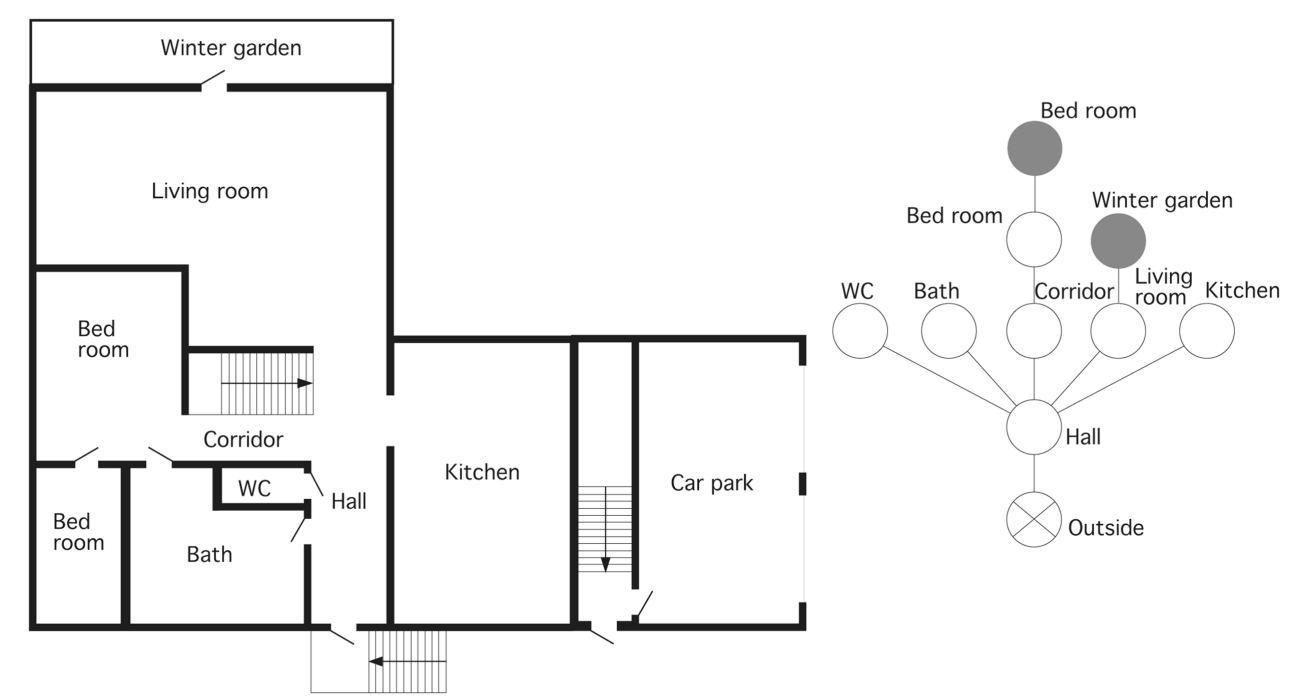

Fig. 1.2 Floor plan of the refurbished bungalow (left) with a corresponding justified graph (right)

As shown in Fig. 1.2, the removal of only two walls and adding the former porch as a winter garden to the spatial arrangement have a significant impact on the bungalow's spatial configuration. From the former three bedrooms (Fig. 1.1), now two bedrooms, only one bedroom remains a dead-end space. In Fig. 1.1, all three bedrooms were dead-end spaces. From this architectural example, we can derive a clear relationship between how people organise their lives and shape spaces for their activities and needs. Vice versa, these spatial setups shape the possibilities and limitations of human activities.

In general, the relationship between space and society is conditioned by degrees of accessibility, visibility, permeability, adjacency, openness, and enclosure in the built environment. Therefore, operational theories and corresponding methods for analysing spatial relationships contribute to planning and designing cities from an architectural scale to a citywide scale suitable for its users. The question arises on how we can understand spatial patterns linked to human activities for entire cities. A city is definitely more complex compared to a single bungalow. Therefore, it is challenging to develop a comprehensive understanding with an underlying theory about how cities function spatially and socially. For comparing cities and for evaluating 'before and after conditions' of urban interventions, we need to have operational scientific methods for analysing urban forms.

For an analytical comparison of cities, we encounter two main approaches in the elementary theory of science, the normative and descriptive approaches. For a normative approach, the city is understood through the lens of a universal subject and established standards. This rational or blueprint planning approach offers descriptions on how successful cities should be planned and designed, but lacks evidence for how cities will function according to implemented norms and standards. In contrast, a descriptive approach focuses on how the city functions. Normative statements about how cities and selected urban areas should be planned and designed rely on a careful descriptive understanding and explanation of how they currently function (van Nes 2017; van Nes and Yamu 2020). In the arena of functional or descriptive theories of city form, examples are the books from Jeremy Whitehand (1981), Pierre G. Gerosa (1992), Kevin Lynch (1960), Alexander R. Cuthbert (2007), Michael Batty and Peter Longley (1994), Michael Batty (2007, 2013, 2018), Christopher Alexander et al. (1977), Michael R. G. Conzen (1960, 2004), Michael P. Conzen (2018), Gianfranco Caniggia and Gian Luigi Maffei (2001), Guiseppe Strappa (2014), Giancarlo Cataldi (2018), Vitor Oliveira (2018, 2019), Philippe Panerai, Jean Castex, Charles DePaule, and Ivor Samuels (2004), Bill Hillier and Julienne Hanson (1984), and Bill Hillier (1996).

Applied methods for comparing cities and studying their morphologies must have a high level of testability, objectivity, falsifiability, explanatory power, precision, systemic structure, empirical support, applicability, and generality (Troye 1994, p. 30). They must be applicable to different morphological typologies independent of their economies, cultures, and societies. This allows us to predict the socio-economic effects of urban interventions and to understand the space-society relationships of cities. Falsifiability and testability also relate to the work of Karl Popper in his book Conjectures and 
Refutations: The Growth of Scientific Knowledge from 1963. Robust theories and methods are context independent and are applicable to all spatial systems at all scales independent of types of societies, political structures, or cultures-from hamlets, villages, and towns to cities and regions. Thus, they have a high degree of generalisability. This also applies to space syntax theory and methods. Its high level of falsifiability and testability lies in the fact that the method has been developed through years of trial and error, and the methods have been tested and applied in built environments worldwide (Yamu et al. 2021).

Space syntax as a static street network model indicating spatial dynamics is simple, but robust, allowing for quick syntactical analysis of a wide range of cases (Yamu 2014). Its robustness allowed space syntax to survive many criticisms (Ratti 2004; Cuthbert 2012). Space syntax has been undergoing constant development through methodological improvements, increased computational power, and its growing application in various fields.

\subsection{Established Traditions for the Physical Form of Cities}

There are currently three established traditions for the physical form of cities: urban morphology, place phenomenology, and the urban network approaches. Each tradition addresses different spatial components of the built environment allowing all approaches to be complementary to each other to support a comprehensive understanding about cities. The aim in this section is to give a brief overview of how space syntax relates to other established research methods on built environments.

\subsubsection{Urban Morphology Tradition}

Urban morphology assumes that the city can be understood and analysed by its physical form. Three main schools in urban morphology tradition emerged over several generations of scholars, namely the school of Muratori in Italy (Caniggia and Maffei 2001; Cataldi et al. 2002), the school of Conzen from the United Kingdom (Whitehand 1981; Conzen 2004), and the school of Versailles in France (Gerosa 1992; Panerai et al. 2004).

The first beginnings of urban morphology as a research tradition date back to the 1840s in Germany. In 1841, German geographer J. G. Kohl published morphological maps and a buildings height diagram of Moscow. By the 1920 and 1930s, an urban morphology group was established in Germany. Inspired by the work of the late Otto Schlüter, M. R. G. Conzen drew several morphological maps of Berlin as a student between 1926 and 1933. During the Nazi regime, Conzen fled from Germany to England where he continued his research (Whitehand 1981; Conzen 2004). Together with Jeremy Whitehand, the Anglo-German school of urban morphology wes established at Birmingham University. It was Conzen who made the historical-geographical foundation for analysing urban form with Whitehand as a key contributor for the definition of urban morphology as a discipline with concepts, methods, and understandings on urban transformations (Oliveira 2019, p. 27). Well-known scholars, such as Michael P. Conzen, and Anne Vernez-Moudon, are intellectual offspring from this school (Oliveira 2019).

M. R. G Conzens 'philosophy' consists of classifying the intrinsic properties of space. It made distinct classes or grouping of spatial or physical artefacts based on how they immediately appear to us. He writes that:

The division of reality into phenomenal classes for the purpose of separate investigation may proceed by grouping phenomena according to their apparent differentiating or dominant characteristics which may be those of inherent particularity of 'objective' nature, of spatial arrangement, or of temporal arrangement. Thus investigating becomes particularized or phenomenally orientated. Selected phenomena or phenomenal classes becomes the focus of attention, being the central object of investigation by which separate fields of knowledge are identified (Conzen 2004, p. 15).

The elements of the German-Anglo urban morphological approach are as follows: (a) time, (b) economic factors, (c) the provenance of agents, (d) governmental control of development, (e) conflicts between the forces of preservation and changes, (f) town plans on paper that are both realised and not realised, (g) frenetic building activities, (h) infill and piecemeal redevelopment, and (i) the influence of the decision-making process (Oliveira 2019, p. 2). All these societal forces have to be taken into consideration for understanding the transformation of the physical elements of the urban landscape, consisting of streets, street blocks, spaces, plots, buildings, and building elements (Oliveira 2019, p. 81). 
The Italian school of urban morphology emerged in the 1950s with Saverio Muratori's studies on building typology and urban texture for Venice and Rome. Through these studies, Muratori developed an understanding of urban architecture based on the historical idealism of Benedetto Croce (Cataldi 1991). Building on Muratori's work, Caniggia and Maffei (2001, p. 25) compared different anthropic structures of building typologies. They claimed that the heritage of civil continuity substantially belongs to the typological processes, which remains hidden from the intentional components that the architect superposes on his work (Caniggia and Maffei 2001, p. 41). Caniggia and Maffei's works consistently compared contemporary and past buildings products, focusing on what exists and what appears in a built environment. They studied historical analyses of the building typologies, how society has influenced the building type, and the intentions of the buildings' designers/architects. While the German-Anglo school focused more on the intricacies of the town plan itself, the Italian school focused on the evolution of building types and their settings within the ground plan (Conzen 2018, p. 127). Hence, the Italian school is often named "the school of urban typo-morphology" (Caniggia and Maffei 2001, p. 32).

The elements of the Italian school of urban morphology consist in (a) analysing built objects, (b) analysing the interpretation by the designer of the object who observes the built landscape, the problems it poses and the transformative potential that it presents, and (c) the possible congruent transformation forecast in the built reality (synthesis). The forecast considers all the components that contribute to the urban transformation, including the contributions of disciplines different from architecture (Strappa 2018, p.159). The architecture of the built objects are seen as a process, which requires the reading of urban form as a continuous transformation process through time. Therefore, their analytical approach consists in registrations or observations of man-made objects from different time periods. Caniggia and Maffei also investigated how buildings are influenced by the routing system (the street system). New buildings, also coined infill buildings, that are constructed in areas with an existing plot and street pattern tend to adjust themselves to existing urban morphological structures (Caniggia and Maffei 2001, p. 135).

Aldo Rossi, inspired by Muratori's work, showed that the different physical elements of the city are driven by political, economic, and social forces (Moudon 1997, p. 5). As Rossi claims, explanatory interpretations of urban form based solely on political, social, and economic aspects are insufficient. Rossi had a particular interest in the residential areas, because these areas consist of small internal components, such as urban blocks with many single small plots. These small internal components are generators of a specific urban form and are capable of accelerating the urbanisation processes. These areas undergo continuous transformation processes, where some artefacts (named primary elements) constitute the future form of cities. Rossi rejected the historical dimension. However, he was aware of the role of technical, social, and economic changes affecting the transformation of cities (Marzot 2002, p. 67). The Norwegian architects Karl Otto Ellefsen and Dag Tvilde applied Rossi's principles for analysing a city's historical development based on Rossi's contribution (Ellefsen and Tvilde 1990).

The French school of urban morphology emerged in the 1960s in Versailles. The main focus of the research of Philippe Panerai, Jean Castex, and Charles DePaule is the historic descriptions of the morphology of urban blocks. The role of the social, technical, and economic setting and the influences and design intention of the architects at that time are seen in relation to the design problem that has to be solved. All these aspects influence the shape of the blocks. Panerai, Castex, and DePaule's work represents a historical development on how the placements of buildings contribute to changes of closed building blocks towards freestanding buildings dissolving urban blocks. As Panerai, Castex, and DePaule claim, studying the urban block enables understanding the interplay of differences and continuities. The urban block represents the transition from the dwelling to other spaces that are both adjacent to it and a part of the larger urban spatial system (Panerai et al. 2004, p. 124). The main message is that blocks consisting of different sets of elements (buildings) are more robust when these buildings change without affecting the overall plot arrangement, whereas a large freestanding building on a plot is incapable of adapting to changed circumstances (Panerai et al. 2004, p. 200).

While the school of Conzen takes a historical-geographical approach focusing on the city, the fringe belts, and the surrounding region, the schools of Muratori and Versailles focus more on the urban block, various building typologies, and the influence and intentions of the architects when shaping the vernacular buildings at that time. The Italian morphological tradition has acknowledged a close link between tradition and innovation (Marzot 2002, p. 61), whereas the German-Anglo morphological research tradition takes whole regions into account. As M. R. G Conzen claims, urban geography is a part of 
regional geography. As he writes, "Human society can control and change the geographical substance within that complex only within limits, and must respect and preserve its systematic balance as a whole as well as in its parts, or else will upset it as its peril" (Conzen 2004, p. 36).

All tools and morphological analyses from urban morphology researchers are based on the following three principles (Moudon 1997, p. 5):

(a) The buildings and their related open spaces such as plots, lots, and streets form the fundamental physical elements/artefacts that define urban form.

(b) Urban form can be understood at different levels of resolution, namely the building and its lot, the street and the block, the neighbourhood and the quarter, and the city and the region.

(c) Due to continuous transformation and replacement, urban form can only be understood historically (post-diction).

The principles that most urban morphology scholars are using are defined as follows. The city is a 'manufact', which is the sum of all its built-up elements, where each element is defined as an 'artefact'. Some of these artefacts constitute the future development or transformation of a built environment. An artefact of this kind is a 'primary element'. Examples of primary elements are railway stations, amphitheatres, events such as a fire, or a city plan. As cities continuously transform, sometimes the artefact itself is no longer visible, but its manifestation might remain inherently visible in land subdivision patterns, street patterns, or building patterns. Urban transformation is influenced by technical, political, and societal changes. Some urban areas transform faster than others, while other areas remain stable over a long period of time due to their artefacts' collective memory for their inhabitants.

The study of urban morphology has contributed to the classification of artefacts, in particular to building volumes, shape of urban blocks, street patterns, and land subdivision patterns. Herein, the Krier brothers with Robert Krier in the lead introduced a classification that distinguishes between internal and external spaces. "Internal space is the sum of all indoor spaces and a symbol of privacy. External space is conceived as space for unobstructed movement in the open air. It includes public, semi-public, and private zones" (Krier 1984, p. 15). Following from this, R. Krier distinguishes between subjective and objective factors. For him, the judgement of taste is purely subjective. With regard to objectivity, he established a spatial typology and a morphological classification of the urban space shaped by buildings. Krier defines the street and the urban square as the two basic external elements of urban space, and he believes that the urban square is primarily to "let man discover his usage of urban space." Houses grouped around an open area create the urban square. In contrast, streets result from the spreading of a settlement. "They come into being once houses are built on all available space around the square they form" (Krier 1984, p. 17).

Krier's urban space typology recognises three main groups in line with their geometrical patterns identified in urban figure ground maps, namely triangles, circles, and squares. By including how building heights and building sections affect urban space, he completes his morpho-typological approach. Furthermore, with examples from historical places connected to identified geometrical patterns, he connects his approach to historical heritage. Krier tried to develop a method for studying urban order in a systematic way through urban form. However, his work cannot be regarded as a comprehensive urban theory because it does not allow for a comprehensive investigation of a city in its entirety. His descriptive approach confines itself to the registrations of geometrical shapes of urban spaces and to grouping them under various labels on a local scale. Different from the three established schools of urban morphology, Krier classified urban spaces according to geometrical shapes instead of the buildings, the blocks, and the lots.

Most urban morphology analyses took a qualitative approach until the 1980s. A recent contribution to the urban morphology tradition is Johan Rådberg's suggestion on how to quantify building density and building form at the same time using a single method. In a project for identifying areas for densification in the Swedish town of Västerås, Rådberg developed in his $\mathrm{PhD}$ research in 1986 a new method with the purpose of developing strategies for densification on the municipality level. Rådberg developed a matrix where he correlated the floor space index with the ground space index. This matrix allowed for the classification of various types of building morphologies and how each type influenced the available open spaces (Rådberg 1996). Other measurements such as the open space ratio and layers (numbers of floors) can also be measured in the same 
matrix. The open space ratio shows how much of the plot is used, and the layers depict how many floors a building has on average for a lot. Rådberg's multivariable density method was applied in the Dutch context by Meta Berghauser Pont and Per Haupt, and they first coined Rådberg's method as 'Spacemate' (2004) and later as 'Spacematrix' (2010).

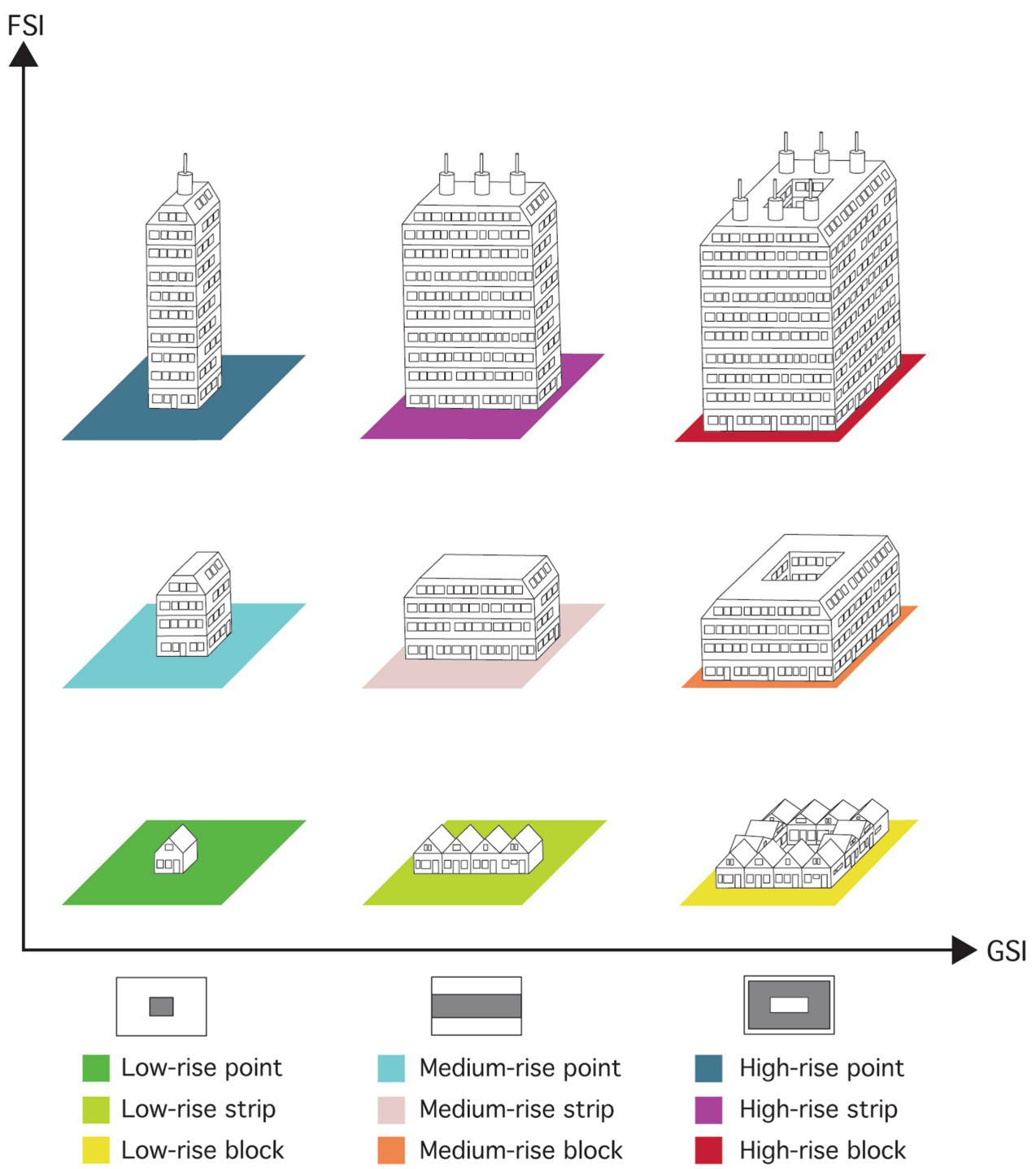

Fig. 1.3 A simplified illustration of Spacematrix showing the floor space index (FSI) and ground space index (GSI)

In the Spacematrix diagram in Fig. 1.3, the category of building density is classified into low-rise, mid-rise, and high-rise buildings depending on the number of floors. The category of building types is classified into point-type, strip-type, and block-type depending on the building's footprint. Thus the built environment can be classified into nine types: low-rise point, low-rise block, low-rise strip, mid-rise point, mid-rise block, mid-rise strip, high-rise point, high-rise strip, and high-rise block (Fig. 1.3).

For the category low-rise, the buildings have one to three floors, and for mid-rise they have three to five floors. The high-rise buildings have more than five floors and tend to have a lift. Figure 1.4 illustrates how building volumes in relation to their plot are placed in the Spacematrix scheme. 


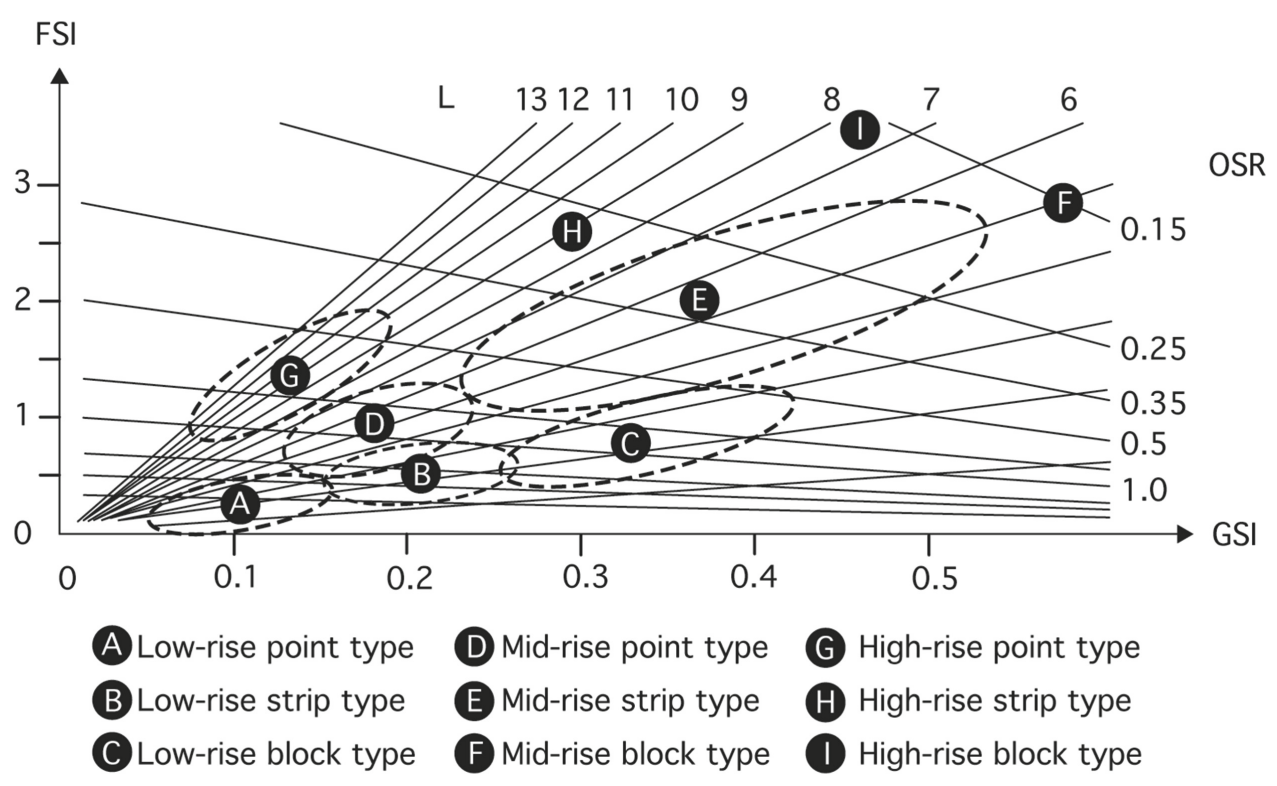

Fig. 1.4 A Spacematrix diagram applied to Dutch and Chinese cities (Ye and van Nes 2014)

Most of the depicted building types in Fig. 1.4 can be found in many towns and cities. The building types vary from place to place. For example, high-rise block types are seldom found in Scandinavian towns, whereas low-rise point types are seldom found in places with land scarcity such as Tokyo, Hong Kong, and Singapore.

The use of the Geographic Information System (GIS) and current data availability with information about plot sizes, buildings, and their numbers of floors allows a quick and easy aggregation of data. For getting a fast overview, examples can be manually classified using the information from Fig. 1.4. Following this, we applied the classification of Spacematrix to the figure ground map of the town centre of Bergen in Norway (Fig. 1.5).

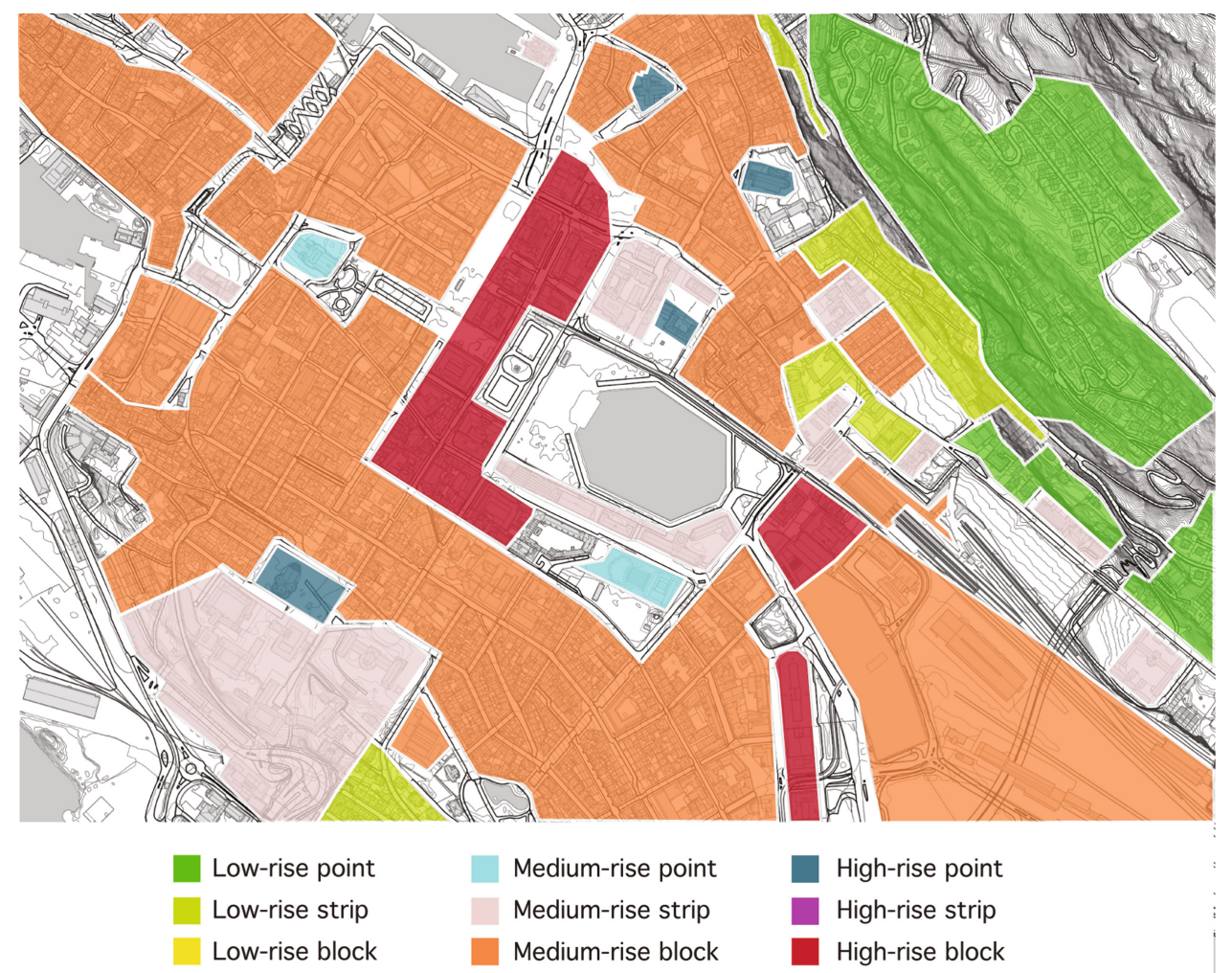

Fig. 1.5 Application of Spacematrix to the town centre of Bergen in Norway 
Yet another recent quantitative approach in the urban morphology tradition is Joost van der Hoek's (2010) triangle matrix, the so-called 'Mixed-Use Index' or MXI, that is used to distinguish degrees of mono-functionality versus multi-functionality of urban blocks. Urban areas with only one function, such as dwellings, working places (industrial areas or office parks), and amenities (leisure activities like sports, shopping, etc.) are defined to be mono-functional. Urban areas are bi-functional when two of these three functions are present, and they are multi-functional when all three functions are present (van der Hoek 2010). The original MXI model measured the percentage of housing, working space, and amenities occupying urban blocks. The function 'housing' included various residential dwellings such as apartments, condominiums, and townhouses. The function 'working' encompassed offices, factories, and laboratories. The function 'amenities' covered commercial facilities such as shopping centres, schools, and universities in addition to leisure facilities such as sporting arenas, cinemas, concert halls, and museums. Thus, MXI is defined as depicting an urban block's percentage of housing, working, and amenities simultaneously.

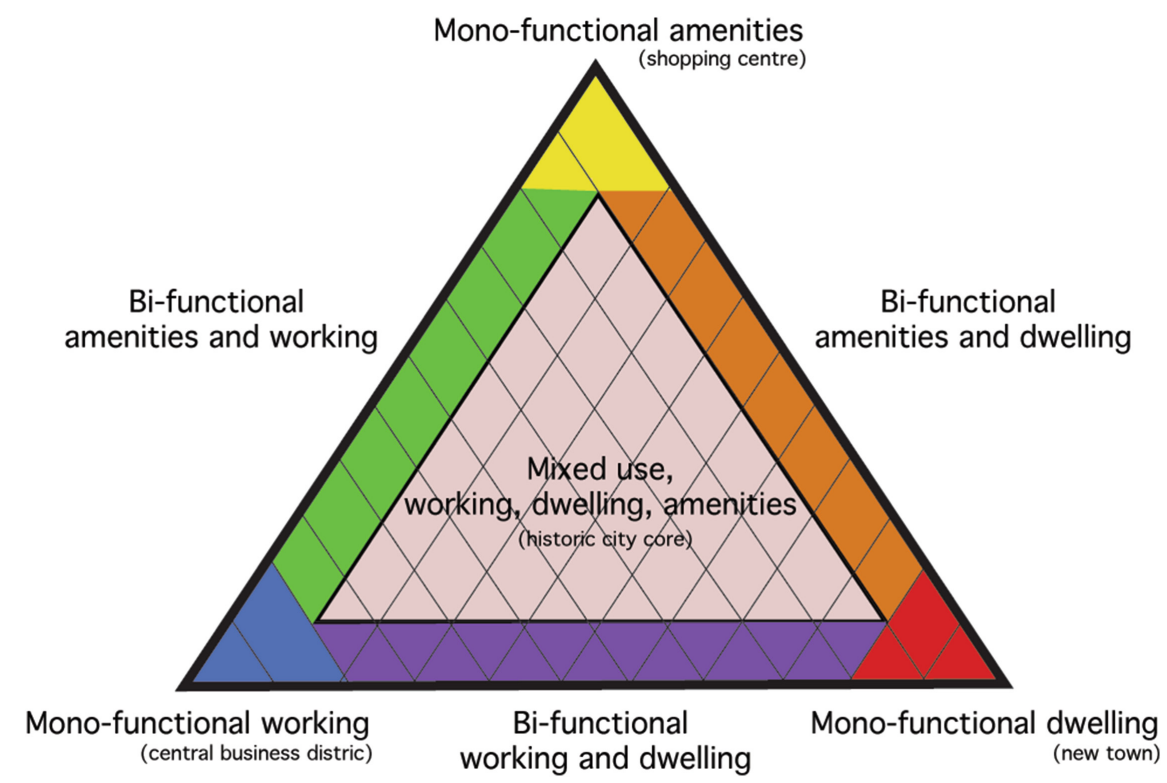

Fig. 1.6 Van Hoek's MXI triangle matrix

MXI can be applied to large urban areas thus allowing for meaningful results (de Koning and van Nes 2019; Ye and van Nes 2013, 2014; van Nes et al. 2012). The misfit of this triangle matrix is that the margin of the function leisure under the category 'amenities' can also fall under the category 'working places'. Moreover, shops and cafés can be both working places and leisure places. Despite such shortcomings, the MXI method is useful for describing urban areas' degree of mono-functionality versus multi-functionality.

Figure 1.6 shows an MXI diagram where the mono-functional areas are located at the edge of the triangle and multi-functional areas such as historic city centres are located in the triangle's centre. Historic city centres tend to have a balanced land use with a mixture of dwellings, working places, and amenities. Again, we apply this method to the figure ground map of Bergen's town centre in Fig. 1.7. Here, only four categories of functions are used, namely mono-functional dwelling, mono-functional working, mono-functional amenities, and mixed use. The mixed-use areas contain more than one function. Juxtaposing the MXI map with Spacematrix, we can see that urban areas with high floor space index and high ground space index also have a high degree of multi-functionality. In conclusion, the degree of land use diversity is related to building density. 


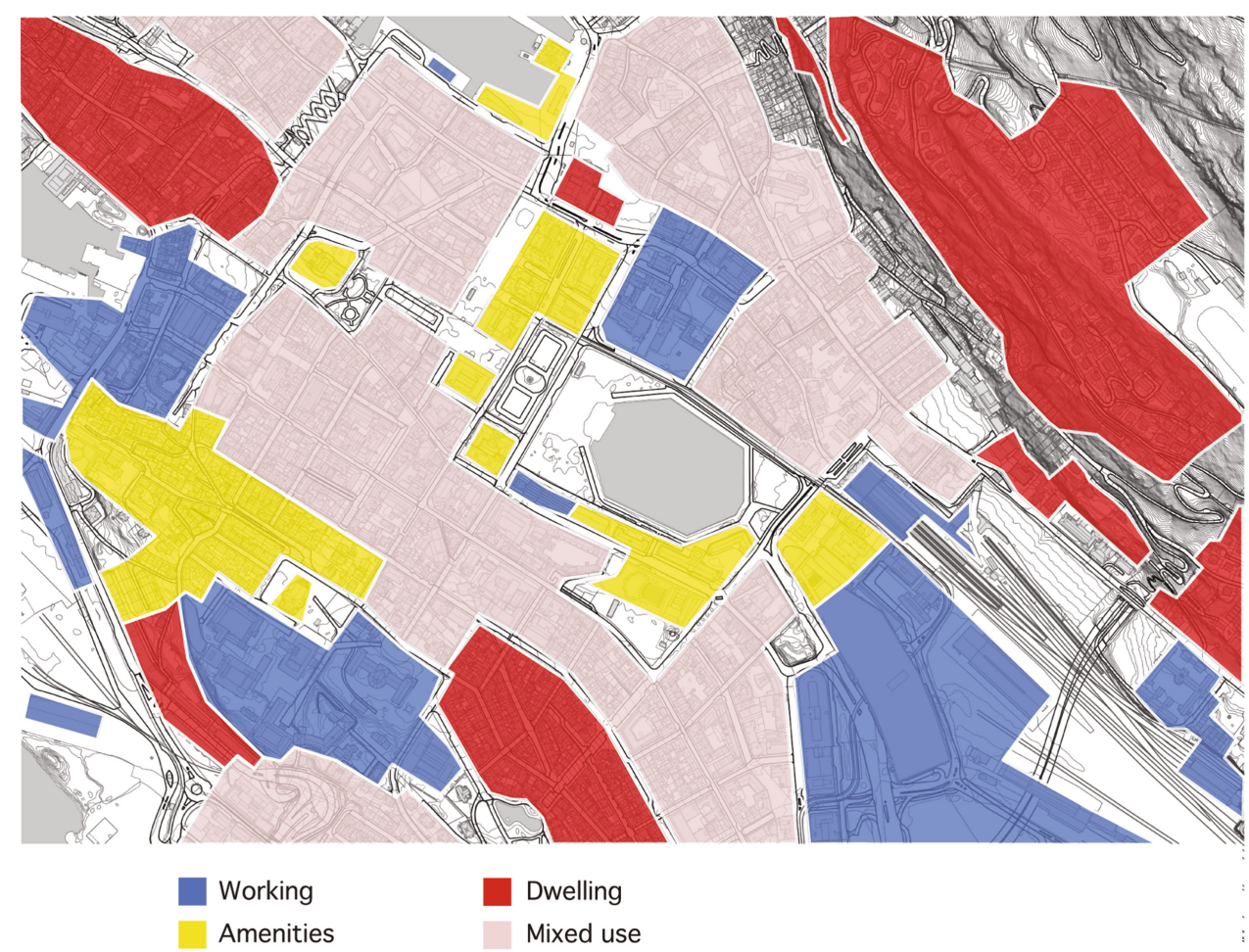

Fig. 1.7 Application of MXI to Bergen's centre in Norway

Through the use of GIS, space syntax research can be merged with the quantitative parts of urban morphology research. These correlations have contributed to broadening our understandings of how cities work and how various spatial and physical elements are interrelated with one another. In Chap. 6, we will elaborate on how these correlations have contributed to new theories on how cities function.

\subsubsection{Place Phenomenological Tradition}

The place phenomenology approach describes the sphere of a place based on Martin Heidegger's work Bauen Wohnen Denken [Building Dwelling Thinking] from 1951. The phenomenological movement was a counter-reaction to the positivistic approach in natural sciences. While positivism explains reality with mathematics and focuses on objects, phenomenology describes impressions of reality as it immediately appears to us. To illustrate both approaches, Fig. 1.8 depicts how water can be represented and experienced. The image to the left shows its chemical formula, and the images in the middle and to the right show some scenic impressions of a waterfall and a glacier. 


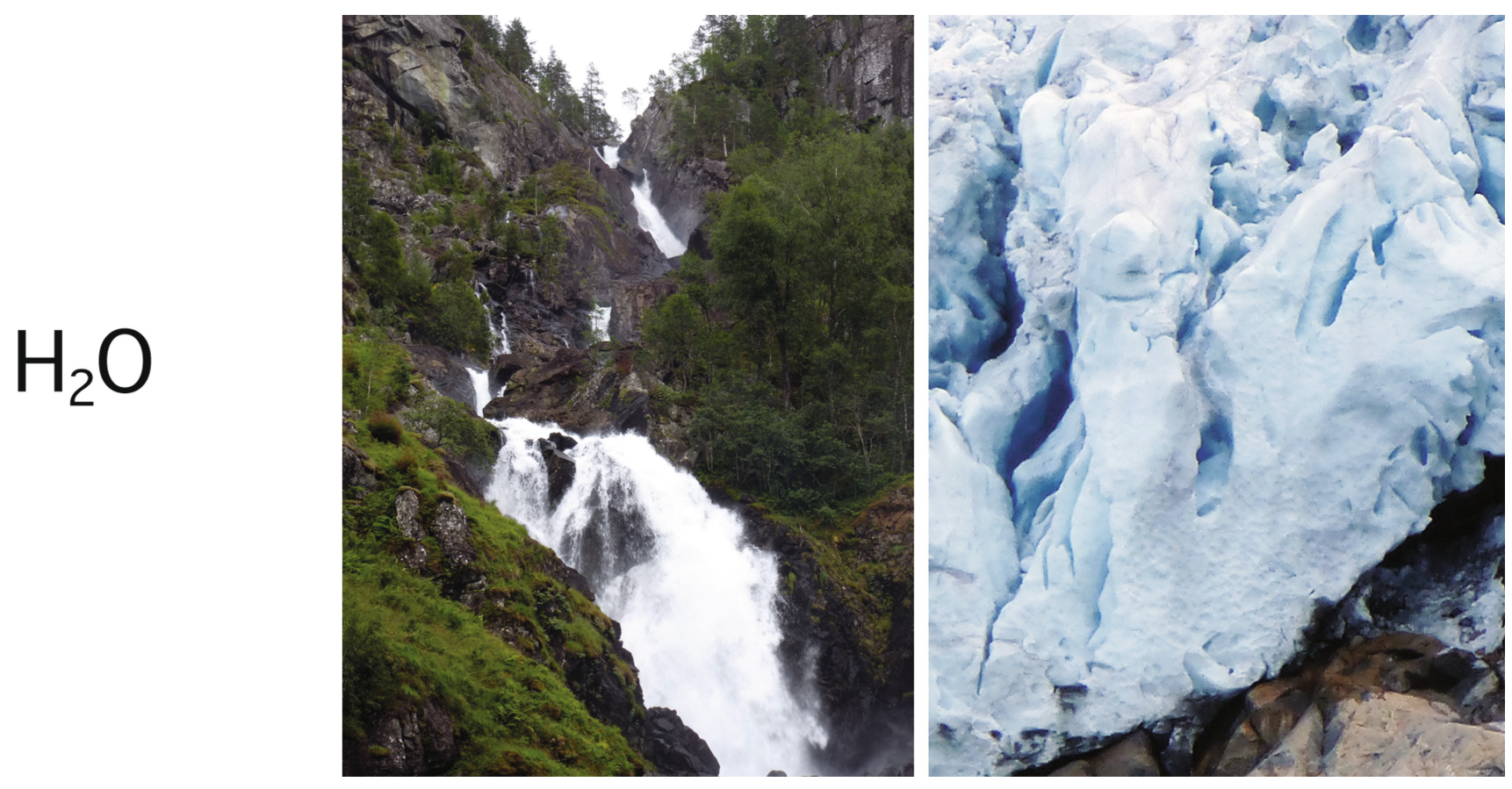

Fig. 1.8 A positivistic (left) and phenomenological (middle and right) approach for water

Christian Norberg-Schulz (1980) builds upon Heidegger's work for the arena of architecture. For him, Heidegger's concept of existential 'space ' includes aspects of 'place' and 'character' complying with basic psychological functions such as 'identification' and 'orientation'. Heidegger proposes existential space not to be a mathematical term, but takes it to stand for a basic relationship between man and his environment. For defining existential space in architecture, Norberg-Schulz suggests, "[...] man dwells when he can orientate himself within and identify himself with an environment, or, in short, when he experiences the environment as meaningful" (Norberg-Schulz 1980, p. 5). This existential space does not differentiate between space and place. However, Norberg-Schulz's understanding of 'Wohnen' [dwelling] is that lived spaces create places. Hence, a place is defined as a space with a distinctively social character.

An integral description in line with the thoughts of Norberg-Schulz can be applied to describe a place's character. His method does not draw upon quantifiable categories to analyse a place and its hidden laws. Instead, it is about the interpretation of a place as follows:

(1) Understanding a place's genius loci: This is about understanding a place's distinctive atmosphere, or the 'spirit of a place'. How places are experienced or perceived depends on the identification and description of their architectural psychological conditions. Herein, Le Corbusier summarises in his work Vers une architecture, "[...] Architecture is a thing of art, a phenomenon of the emotions, lying outside questions of constructions and beyond them. [...] Architectural emotion exists when the work rings within us in tune with a universe whose laws we obey, recognise and respect. When certain harmonies have been attained, the work captures us. Architecture is a matter of 'harmonies', it is a 'pure creation of the spirit'" (Corbusier 1971 p. 23).

(2) Identification of a place's spatial order: In this respect, Norberg-Schulz's analyses consist of the identification of the spatial features of an urban environment. It is meant to find out, for example, where streets are leading to or what features a settlement's buildings appear to have. Unfortunately, Norberg-Schulz does not propose or justify any conceptual tools appropriate for this purpose. His reference to Lynch's urban-image concepts illustrates that in this second respect, his architectural existentialism aims at a perceptual interpretation of urban orders. 
(3) Definition of a place's character: Norberg-Schulz defines a place's character through (a) the definition of the shapes of the built elements such as building shapes, openings shapes (doors and windows), and ornaments, (b) buildings in relationship to the surrounding landscape, (c) building forms, and (d) the organisation of the interiors and the spaces between them. Inspired by Lynch (1960), for Norberg-Schulz urban space is divided into three types - the street, the square, and the neighbourhood. The square is the centre of the surrounding settlement. It is a place within the place. While the street is a place we move though, the square represents a kind of destination we have reached. The street is not an aim in itself. It connects one place with another. A neighbourhood is defined as a place where the buildings are located close to one another. It is a place where people live together.

Some of Norberg-Schulz's PhD students developed analytic methods based on his theories. The most well-known approaches are those of Thomas Thiis-Evensen (1987, 1992) and Anne Marie Vagstein (1999). Thiis-Evensen set up a classification of building openings, building shape types, and street types. This was in contrast to Vagstein, who developed a manual for qualitative place analysis. However, the operationalisation of their approaches has not been successful in practice. The reason is that Vagstein's method is rather subjective and has a lack of precision for the elements used, and Thiis-Evensen's method on archetypes in architecture is useful for the classification of building levels, but not on a neighbourhood or city level.

The most used method from the place phenomenology tradition is the work of Lynch about the "image of the environment' in his book The Image of the City from 1960. A city image may be analysed according to the three components of identity, structure, and meaning (Lynch 1960, p. 8). He relates physical and qualitative attributes of identity and order to a mental image. He is not only concerned with urban form, but also with the form in which urban order is perceived by its residents (Lynch 1960, p. 3). The acquisition of an image is a reciprocal development between the observer and the observed.

For him, the identification of an object, e.g. an urban environment, consists of the possibility to distinguish it from other objects and to recognise it as a separate entity. An object's image thus must include the pattern of its relation to an observer and to other objects. Meaning is a subjective matter on which physical manipulation has less influence than it does on identity and structure (Lynch 1960, p. 8). Lynch uses a number of other terms such as an environment's legibility and visibility and thereby indicates his intention to provide an analysis of urban form based on perception. For Lynch, the environmental image is a function of permitting purposeful mobility. Lynch introduces five basic elements:

(a) Paths are channels through which people are moving.

(b) Edges are linear elements the observer does not consider to be paths.

(c) Nodes are strategic spots people can enter.

(d) Districts are sections of the city conceived to have a 2D extension with or without a particular character.

(e) Landmarks are points of reference visible to the observer.

Lynch applies these elements to generate visual form maps. These maps allow one to identify general visual problems and strengths, critical elements, and elements' interrelations, including their detailed qualities and possibilities for change.

Figure 1.9 depicts a visual form map of Oslo representing Lynch's five elements. The relative importance of these elements for a 'good' city image will vary with different persons in different situations; one will prize an economical and sufficient system, another an open-ended communicable one (Lynch 1990, p. 9). 
Fig. 1.9 Lynch's five elements (a) and a visual form map of Oslo (b)

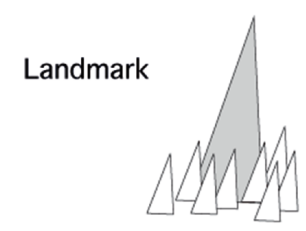

Path

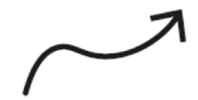

District
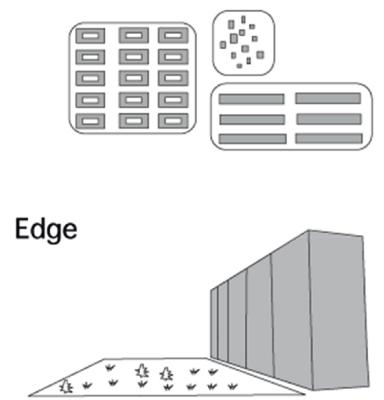

Node

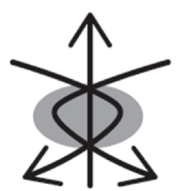

(a) Lynch's five elements

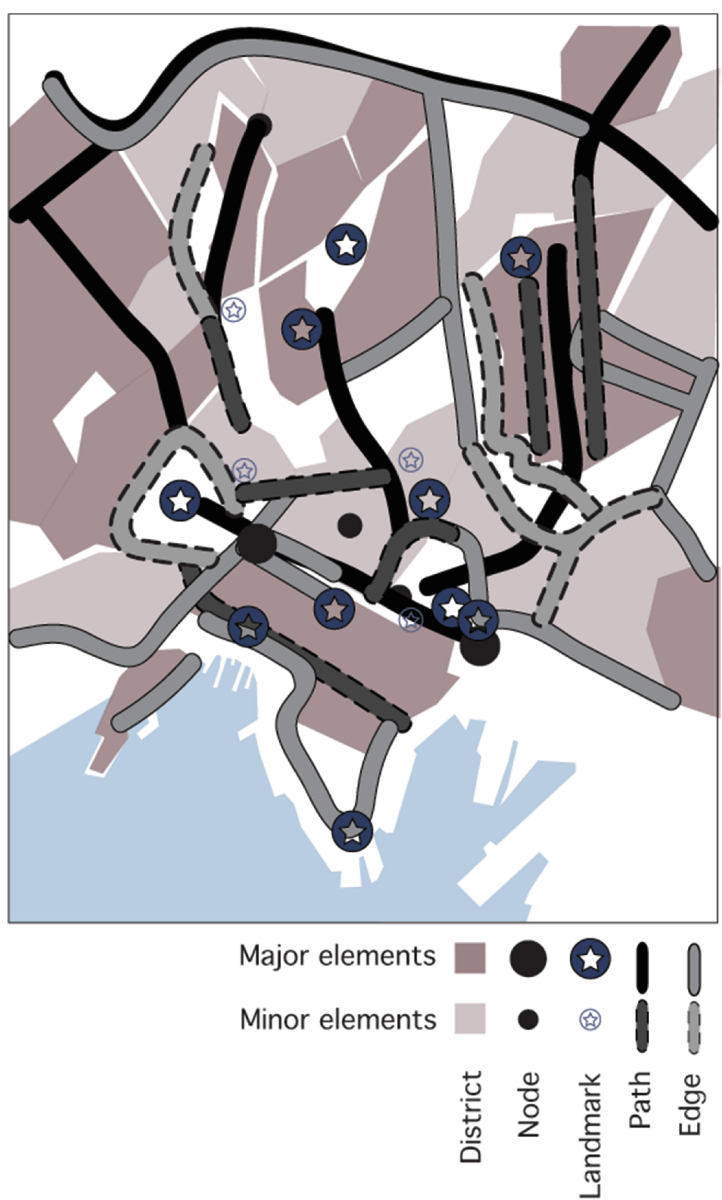

(b) Lynch's method applied on Oslo

Lynch's analytical method is derived from the psychology of perception, and different observers apply Lynch's five elements to draw a visual form map for a chosen city. A significant advantage of his method is that it provides a means to analyse urban form. His approach is based on taking into consideration the relationship between the user and the artefacts of a city. Moreover, he pays attention to visibility, movement, and orientation in a city in relation to physical objects.

According to Kayvan Karimi, a weakness of Lynch's method is the unjustified choice of elements the observer is supposed to take into consideration when designing their image of an urban environment. Lynch does not discuss whether most persons, strangers as well as inhabitants orientate themselves based on these five elements. Yet another problem of Lynch's method is the fact that different observers might perceive some of the five elements differently. For some observers, a ring road might count as a path, while others might take it to be an edge. Therefore, observation maps can vary between observers. Moreover, the transformation of interviews of a city's inhabitants into orientation maps is not free from individual judgements (Karimi 1998, p. 47). 


\subsubsection{Urban (Street) Network Tradition}

The urban network tradition addresses mobility, accessibility, visibility, and orientability (Hillier and Hanson 1984; Hillier 1996; Marshall 2005; Batty 2007). In the field of architecture and urban planning, the urban network tradition addresses how the street network functions as a spatial armature for the socio-economic life of cities. The focus here is thus on space instead of form. It is about the spaces that are shaped by the borders made by physical objects placed in space.

There exist two different approaches-street pattern and street structure. Most researchers of the urban street network tradition focus primarily on the street pattern (Marshall 2005; Klaasen 2004; Dupuy 2008). Street network patterns appear as regular and irregular patterns. Planned and unplanned street patterns include hybrids, and there are various permutations of simpler forms and basic typologies. In addition, different scales are used for describing and analysing urban agglomerations. The diverse combination of different patterns at various scale levels, and thus the hierarchical impact, often reveals differences in accessibility patterns between traditional and modern cities.

In his book Streets and Patterns from 2005, Stephen Marshall introduces the ABCD typology for street patterns. He comments that this typology was developed with the intention of "reflecting typical street patterns that are encountered in different kinds of urban analysis" (Marshall 2005, p. 84). The four types feature different stages of the growth of towns and cities, from the historic nucleus to the suburbs of an agglomeration. Figure 1.10 shows an overview of these four types and how Marshall derives different compositions and configurations from these street patterns.

The A-type represents the nucleus of old cities, especially walled cities. Angularity in combination with a variety of directions generates a rudimentary radiality. The B-type is a typical newly founded settlement. The four-way perpendicular junctions give rise to a bilateral directionality. The C-type describes arterial routes whether constituting the centre of a village, a whole settlement, or suburban extensions along a route. The D-type represents a modern hierarchical layout. It can be compared with the analogy of distribution. The ABCD types can emerge singularly or in a mixed mode, or also be arranged according to the order of centrality in urban systems. In particular, this phenomenon exists in traditional European towns.

For the compositions of street patterns, Marshall applies a geographical map of urban layout, whereas for the configuration he presents a diagram or abstraction of the street pattern type. Marshall uses the distinction between composition and configuration to explore different urban systems and structures with the purpose of revealing the hidden structure of each street network type (Marshall 2005, p. 175).

For quantifying street patterns, Marshall operates with a matrix for which he introduces two types of street junctions and two types of street networks: (a) T-junctions and X-junctions and (b) tree-structured and network-structured street networks. His method first calculates the X-ratio of X-junctions and the T-ratio of T-junctions for the entire urban area street network under consideration. This means simply calculating the percentage of $\mathrm{X}$-junctions and $\mathrm{T}$-junctions for a given street network. In networks only comprising $\mathrm{T}$ - and $\mathrm{X}$-junctions, clearly the sum of the T-ratio and the $\mathrm{X}$-ratio will equal one. 
Historic city centre in Vienna, Austria

Majorstuen area in Oslo, Norway

Street Pattern
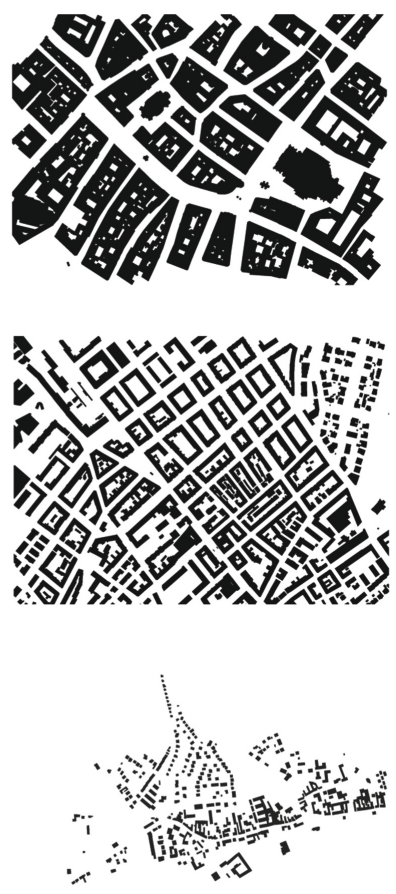

The village Achau in Austria

Atolwijk in Lelystad, the Netherlands

i
Composition
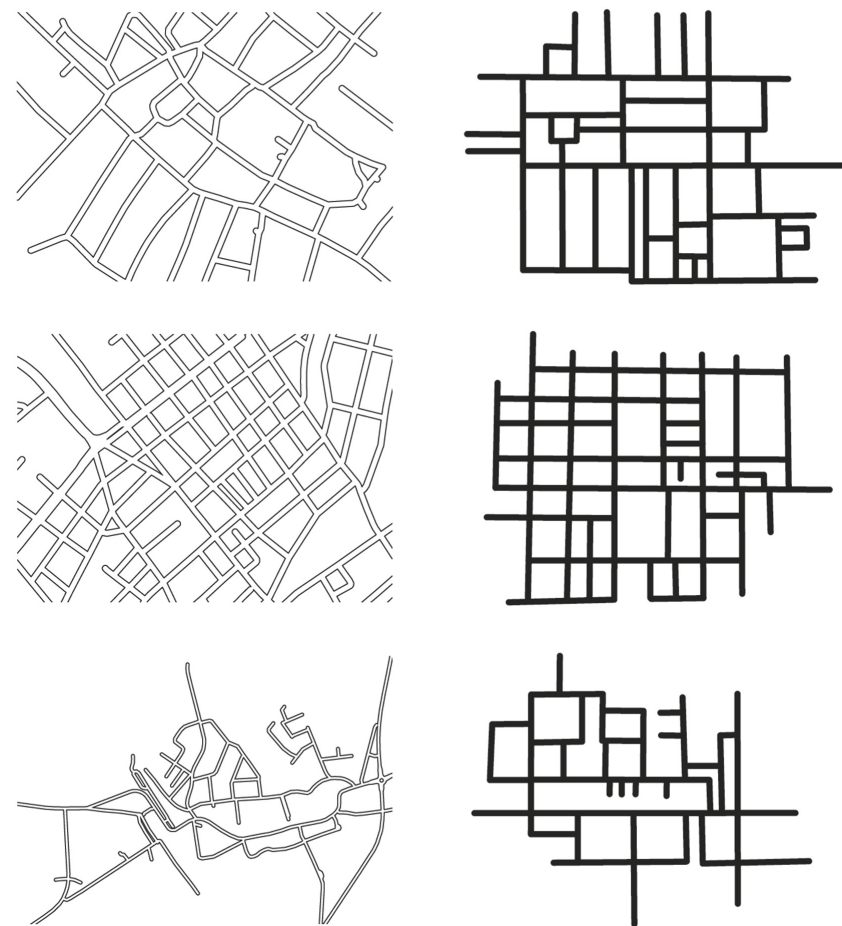

-

$8=-7$ T
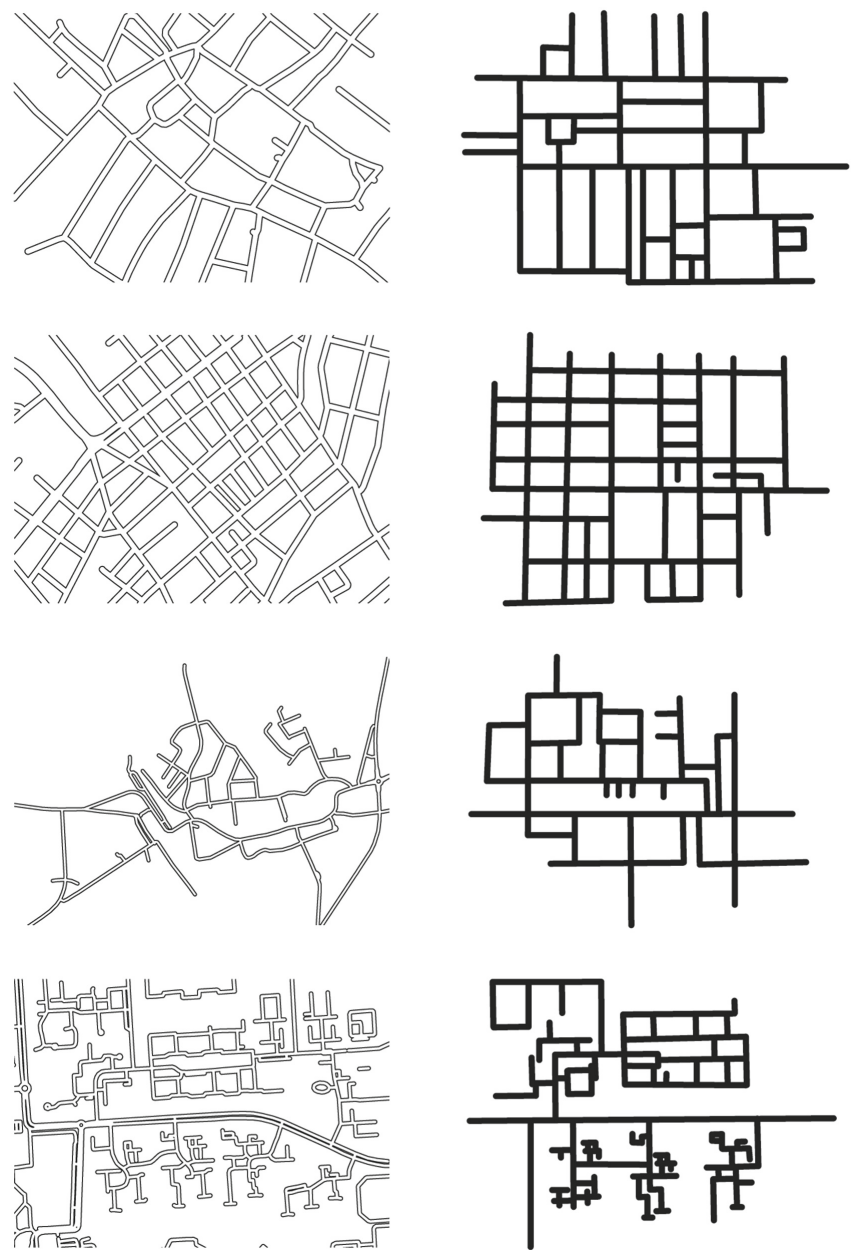

Fig. 1.10 Marshall's ABCD types in compositional and configurational terms applied on urban areas in Vienna, Oslo, Achau, and Lelystad

As Marshall explains, in almost any real street layout there will be a mixture of T- and X-junctions and the corresponding ratios will lie somewhere between zero and one (Marshall 2005, p. 102). In the next step, the cell and cul ratios of the network are calculated. For the cell ratio, the percentage of cells for the whole network is calculated taking into consideration the number of cells and cul-de-sacs. A cell is a structural unit enclosed by street segments. For the cul ratio, the percentage of 


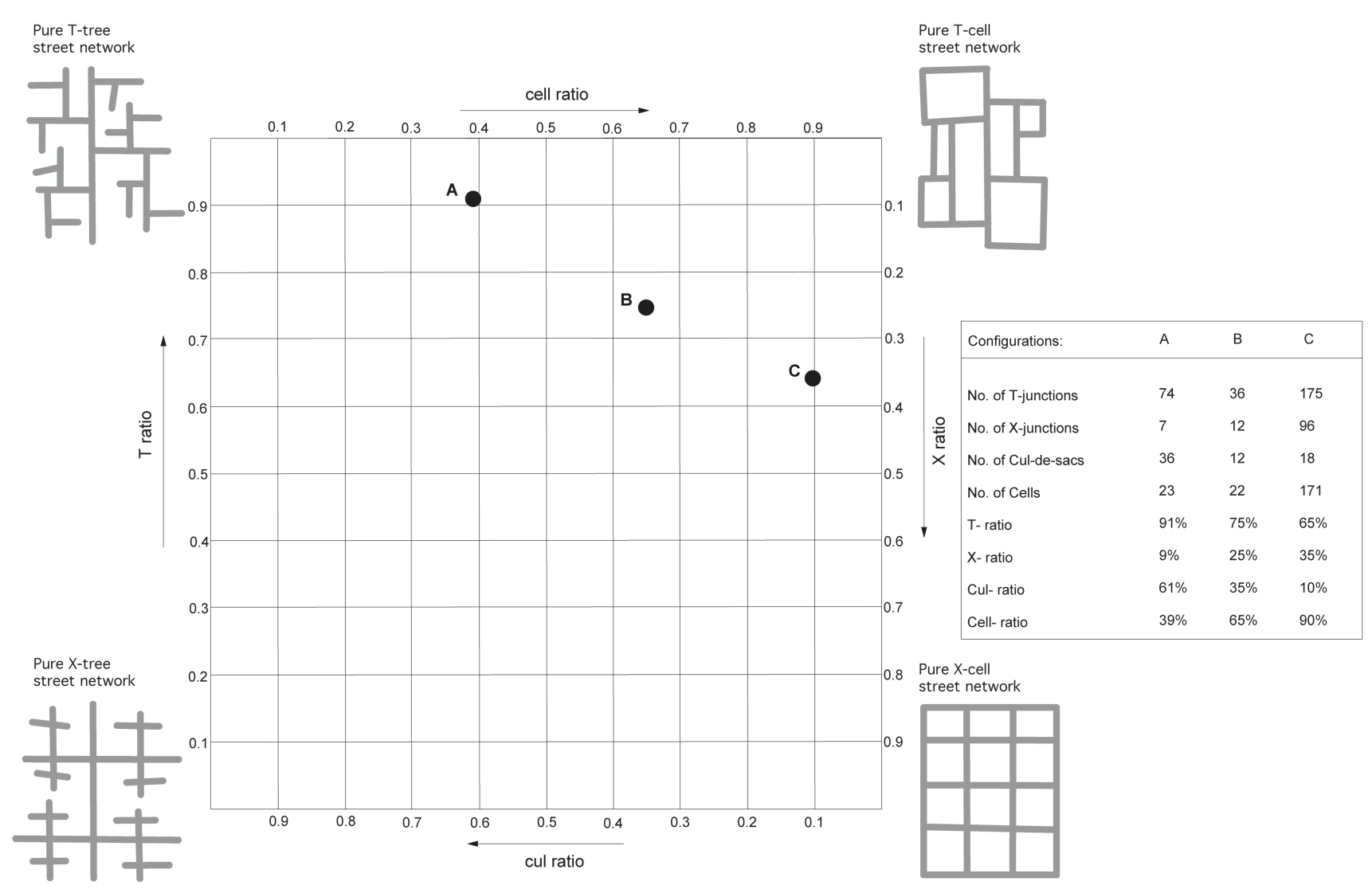

Fig. 1.11 Marshall's matrix applied on three different neighbourhoods in Singapore (A), (B), and (C)

cul-de-sacs is calculated for the whole network taking into consideration cells and cul-de-sacs. The numerical values of the T- and X-ratios are plotted against the cul and cell ratios in Marshall's matrix (Fig. 1.11).

This simple but useful method in the tradition of network representation provides insights into the pattern specification and presents properties such as clarity, coherence, and connectivity in distinct compositional or configurational terms. The graphic presentation allows the demonstration of areas - however precisely of fuzzily identified - in which 'preferred' or 'discouraged' patterns might lie (Marshall 2005, 98).

Another concept used in studying urban areas is whether a street is distributed or non-distributed. When a street is distributed, there is a possibility to leave it without travelling back the same route. Conversely, a non-distributed street is a street with a dead end or cul-de-sac without a through footpath (Hillier and Hanson 1984, p. 78). Distributed streets form a network of possible movement routes, which open up for a mixture of visitors and inhabitants, while non-distributed streets form simple movement routes mainly for inhabitants. The latter tend to create built environments with a semi-public and semi-private street structure. In Fig. 1.12, we show the distributed and non-distributed streets for a town X. 
Fig. 1.12 Distributed and non-distributed streets for town $\mathrm{X}$

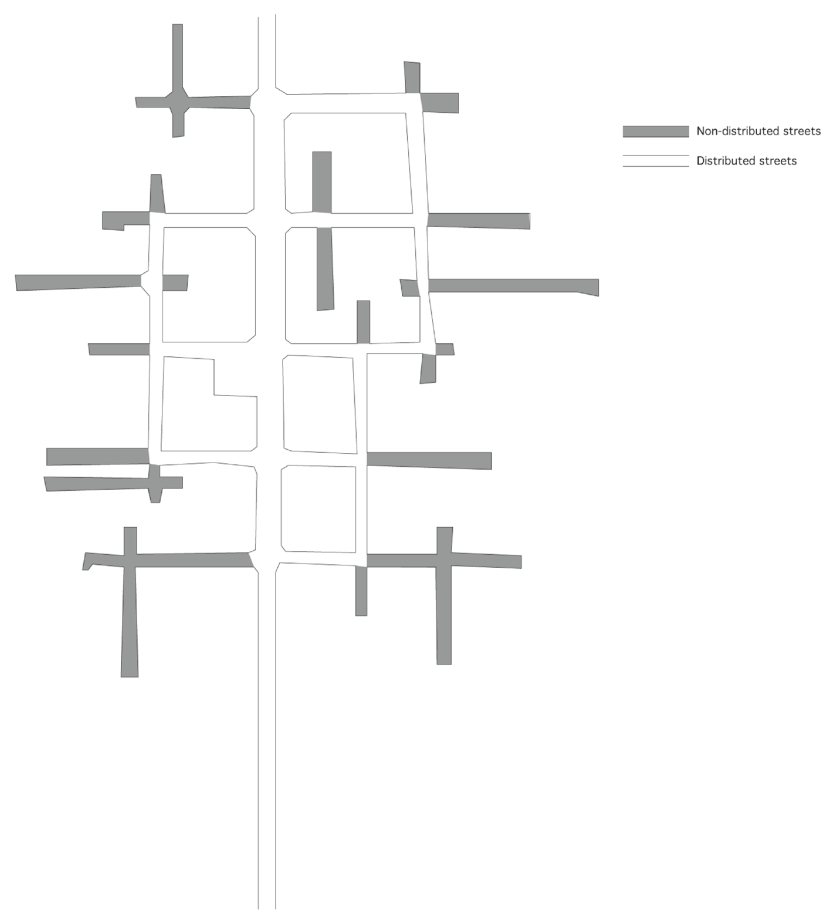

Using Christopher Alexander's (1965) distinction and definition of natural and artificial cities, artificial cities, i.e. planned cities, with a tree structure consist mainly of a non-distributed street structure. Natural cities that have emerged over time consist of a semi-lattice structure and thus incorporate a more distributed street network. Cities with a semi-lattice structure usually have a complex transportation network, and their functions are well integrated. According to Alexander, this structure improves a city's economic development, its safety, and its liveliness. Thus, a distributed street network encourages a mixture of functions and movement patterns, while a non-distributed street network promotes the opposite. Highlighting the difference between a distributed and non-distributed grid on a map indicates the degree of complexity of movement routes for a city.

On a more urban micro-scale level, Job van Eldijk's (2014) work contributes to the registration of street functions connected to street profiles. He tries to understand how the design of street profiles affects its users. Even though he names them 'street functions' based on what kinds of transportation modes the various street types are designed for, his proposed typologies give indications on a micro-scale level about the degree of urban street life.

Van Eldijk distinguishes between four different types: (a) streets only accessible for pedestrians and cyclists, (b) a balanced use of streets for vehicles, bicycles, and pedestrians, (c) streets and roads dominated by vehicle transport with pavements on both sides for pedestrians and bicycles, and (d) roads only accessible for vehicle transport. Figure 1.13 shows how these four street profile types are applied in an analysis of a neighbourhood in Oslo. As research has shown, the balanced street type enhances street vitality and safety for children (Meinert et al. 2019). The results are in line with the presumptions of Jan Gehl (1971) and Jane Jacobs (1960) that pavements are important for generating life on streets between buildings. 
Fig. 1.13 Four different street profiles including functions as classified by van Eldijk (left) and translations of these into a map of the Grefsen area in Oslo (right)
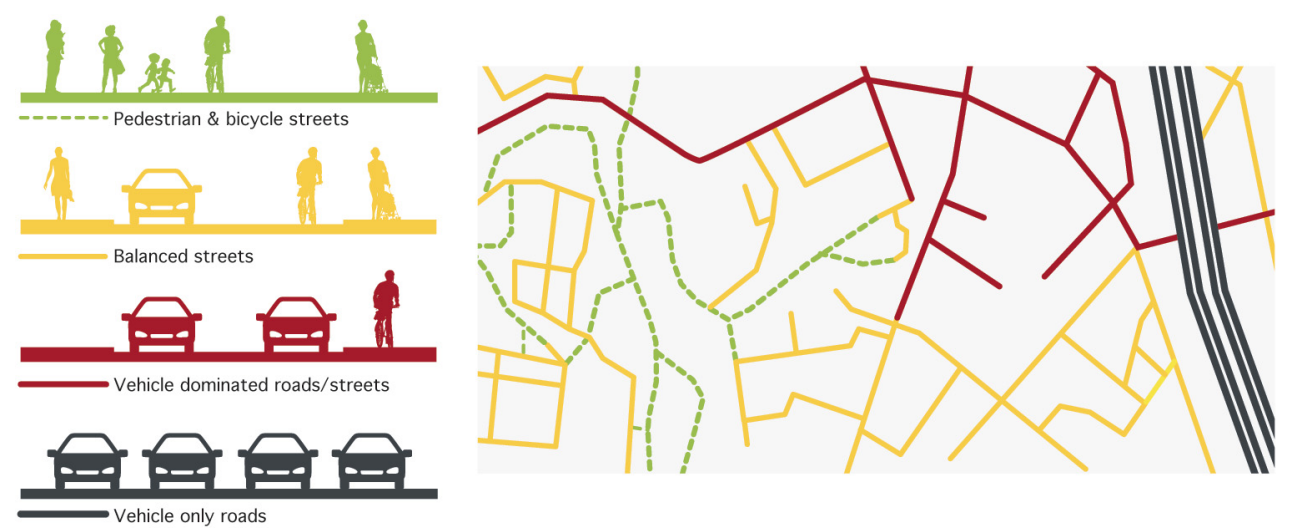

In reality, street profiles can be more complex than those proposed by van Eldijk. One example is the 'shared space concept' by the late Hans Monderman in the early 1990s, consisting of promoting spaces free from traffic regulations. His underlying idea was a self-organisation of street users and permanent negotiation about space (Yamu et al. 2016). This should raise awareness between different users including different modes. To classify the shared space concept, it uses the functional logic of van Eldijk's first type with the transport modes of the second type. Balanced streets tend to be shaped by their adjacent buildings with their entrances facing the street. In contrast, vehicle-only roads lack pavements and tend to be completely non-accessible for pedestrians. In most cases these roads are highways with barriers, nearly impossible to cross safely for pedestrians. However, there exist some dwelling roads with very low car traffic that also lack pavements. These roads are mostly found in built environments with single-family houses (Fig. 1.14).

Fig. 1.14 (Left) Shared space in Vienna, Austria, and (right) a typical dwelling road in Bergen, Norway
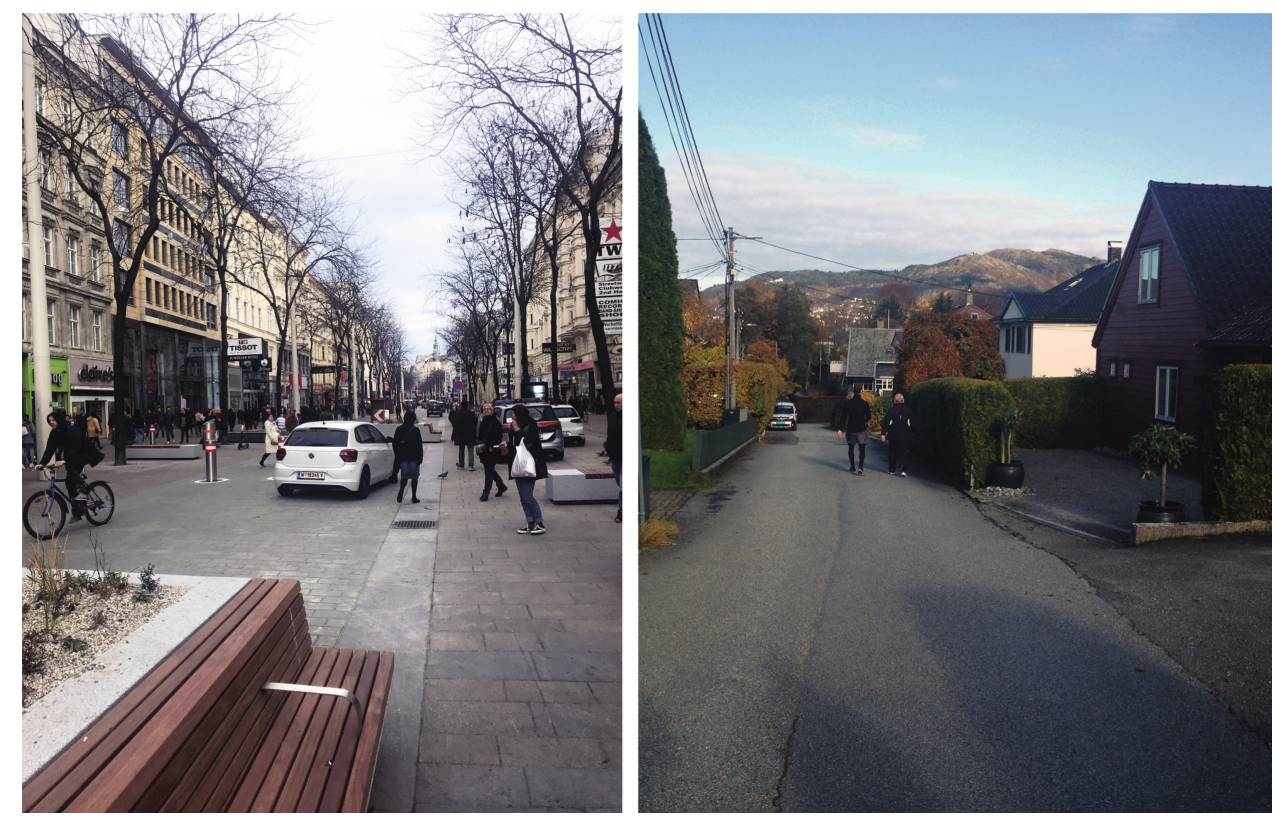


\subsection{The Platform for Space Syntax: Definitions of Urban Space}

Space syntax also falls under the urban network tradition. In contrast with the other urban network approaches that focus on street patterns and compositions, space syntax focuses on street structures or spatial configurations. Through graph theory, the space syntax method is able to calculate the mathematical relationships between spaces. Space syntax was pioneered in the 1970s by Bill Hillier and colleagues at the Bartlett, University College London.

Space syntax is a mathematical street network model that originated in the field of graph theory for calculating topological spatial relationships. The first calculations were made by hand. In the 1980s, computational power and software development allowed the computation of the first models and the calculation of the interrelationships between all the streets of larger towns and cities.

Before the millennium, topological relationships introducing syntactic steps were calculated, and these explain how each street relates to all other streets in terms of the number of direction changes. After the millennium, angular weighting between street segments and metric radii were introduced, and increasing computer power made the calculation of even larger metropolitan areas possible. In addition, the use of geographic information system (GIS) has increased since the millennium. GIS provides the platform for processing georeferenced place-bound socio-economic data, and by building up the spatial analyses model in GIS, place-bound socio-economic data and the results from the spatial analyses can be easily correlated. The importance of GIS is continuously increasing for space syntax for aggregating the large data sets for larger cities and regions.

Interestingly, space syntax is often regarded as a morphological approach (Whitehand 2018), although it differs from the traditional morphology tradition in the definition of the spatial elements and the way they are quantified. Space syntax does not focus on the shapes of physical objects but on the spaces between these physical objects and how these are connected to all other spaces in the built environment. Nevertheless, many studies combine space syntax analyses with urban morphology data such as building density, building height, and land use diversity (Ståhle 2005; Hausleitner 2010; Yamu and Voigt 2011; Ye and van Nes 2014; van Nes et al. 2012; de Koning and van Nes 2017, or Yamu and van Nes 2017 for a synthesis).

What space syntax offers is a theory and method for describing and quantifying the spatial properties of the built environment that shape socio-economic activities. Important contributors for understanding the relationship between physical factors of the built environment and social life in cities are Jane Jacobs (1960) and Jan Gehl (1971).

In her book The Death and Life of Great American Cities, Jacobs addresses the role of the pedestrian in making cities lively. She suggests physical indicators on what kind of spatial framework generates lively and safe cities. Her work includes a discussion about urban blocks, eyes on the streets, clear demarcation between public and private space, and mixed use of functions.

Gehl focuses in his work Livet mellem husene [Life between buildings] from 1971 on the types of activities that create life between buildings. His definitions about necessary (going to work or school), optional (strolling, 'le flâneur'), and social (playing, meeting people, and playing sports) activities are taken from his research from the 1960s and later applied in his architectural practice. Gehl claims that optional activities in particular contribute to life between buildings and strongly depend on the physical qualities of the built environment. Jacobs and Gehl provide an insight into how the degree of urban vitality is coupled to spatial qualities of the public realm. Following the work of Jacobs and Gehl, space syntax provides a toolbox for analysing urban space and testing urban design options to create lively cities and neighbourhoods.

In general, space syntax works with the concept of space. Space is an essential aspect of the built environment, but space is an abstract word. It cannot be touched, only perceived. Space and time are constructions that help people to arrange the world into fitting schemata. It is through physics and mathematics that the terms time and space find an interface to the physical word and therefore an interpretation. In cities, space is formed through existential connections. Through these a meaning and allocation of things, places, boundaries, and qualities can be defined. Through its various definitions of and thoughts about space through time, from Aristotle and Heidegger to Sloterdijk and Lefebvre, the idea about space needs to be assessed with care in its applied context.

Understanding a society's effect on the built environment and vice versa requires a concept of physical space. If human activities manifest in space, then the organisation of these activities affects a settlement's spatial organisation. Thus, social activities can be understood with a reference to the physical structure of the built environment. On the other hand, if the physical structure and organisation of architectural space influences human behaviour, it will impact social activities.

With regard to urban space, we have to distinguish between public and private spaces as discussed by Jacobs (1960). Hillier and Hanson $(1984$, p. 92) state that public space is " $[. .$.$] the result of the arrangement of buildings, and possibly other$ bounded areas such as gardens, parks and the like". The main concern of space syntax in urban studies is to analyse the spatial configuration or spatial structure of public spaces and how they relate to private spaces. 
Hillier distinguishes between 'extrinsic' and 'intrinsic' properties of space. Extrinsic properties determine how spatial units relate to one another. In this respect, we can think of configurative laws of space. If we intend to understand settlements in terms of these laws, such settlements are regarded as sets of spaces. It is primarily the arrangement of elements and topological issues that become relevant, and metriccal properties such as distance are not considered. Urban spaces are regarded as purely extrinsic entities, and they are shape-free. In line with Hillier, it is solely their interrelational aspects or structure that is at hand. Every space has one or more functions either in terms of occupation or with regard to movement (Hillier 1999, p. 1), and the extrinsic properties of space determine both the space's built form and its possible functions.

While extrinsic properties of space consist of invisible structural relationships, intrinsic properties of space are visible, such as the shape, size, volume, pattern, and texture of the physical objects or built mass. Intrinsic properties of space present themselves mostly through geometrical properties, and they account for the articulation of social meaning via the built form (Hillier 1999, p. 1). We have many words for describing intrinsic properties of space, like 'a narrow street', 'a large square', or 'a massive building'. These properties enable us to describe urban artefacts.

In general, the concepts of extrinsic and intrinsic properties of urban space contribute to clarifying the typology concept that is often used in urban studies. Here, we have to distinguish between phenotype (how a built environment immediately appears to us) and genotype (the hidden structure of the built form). This will be elaborated upon in the following sections.

\subsubsection{Intrinsic Properties of Urban Space}

What can be immediately seen is easy to identify and describe. Consequently, many established methods in urban studies deal with intrinsic properties of space-among others, the place phenomenological method of Lynch (1960) and methods from different urban morphology schools (Gerosa 1992; Whitehand 1981; Oliveira 2018; Conzen 2004; Caniggia and Maffei 1981; Panerai et al. 2004). In Fig. 1.15, we describe the intrinsic properties of example town X. The figure ground map of town X depicts the built-up mass and the widths of its streets. The density of the building's footprint or ground space index along the main street is higher than for other streets of the settlement. For the housing types, terraced houses and larger buildings are located along the main street, while detached houses can be found on most of the other streets. The overall shape of the settlement is an orthogonal grid pattern with a high number of X-junctions. For a more elaborate description of town X's intrinsic properties, the existing different architectural styles of the buildings and building typologies, for example, can also be considered.
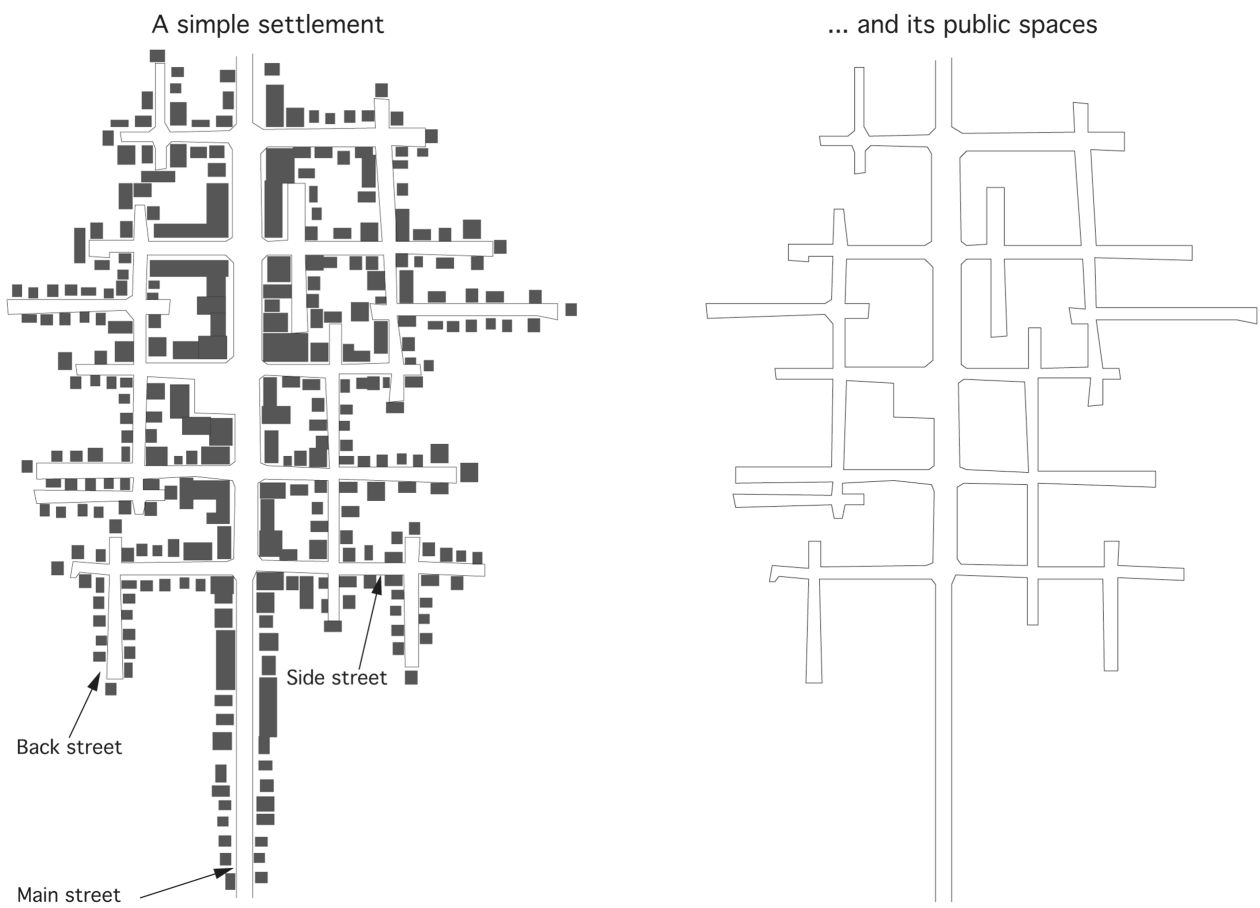

Fig. 1.15 Building morphology (left) and its orthogonal street pattern (right) for town $\mathrm{X}$ 
To understand the present visible conditions of the built environment, comparisons must be made with past conditions. This resonates with Lynch when saying " [...] the city is a construction in space, but one of vast scale, a thing perceived only in the course of long spans of time" (Lynch 1960, p. 1). Thus, history matters. Historic events connected to policies, natural disasters, or socio-economic conditions influence cities and regions and how they have emerged in their present form. Herein, Lynch (1981) in his book Good City Form puts forward that the main force of transformation for human settlements is human motives that influence the built form. Impersonal factors such as natural disasters are only influential on rare occasions. City form has to be understood from its artefacts that consist mostly of built elements. New emerging artefacts can function as primary elements for a future urban trajectory, constituting the future urban pattern and functions (Rossi 1966; Caniggia and Maffei 2001). Examples of primary elements are important buildings, land subdivision patterns, urban development plans, railway stations, and railway tracks.

In his book L'architettura della città from 1966, Rossi advocates for a rediscovery of the traditional European city. He illustrates how present cities and their urban fabric are constituted by the past. Rossi develops three distinct concepts: (a) urban development has a temporal dimension, (b) the city has some spatial continuity, and (c) in an urban environment, there are some primary elements of a particular nature that have the capacity to accelerate or retard urban development.

For example, Rossi (1966) illustrates how the urban fabric follows the building footprint of a previous amphitheatre. While the amphitheatre has disappeared, its shape can be still identified in the urban fabric. For this example, the amphitheatre functioned as a primary element. Figure 1.16 shows two examples of urban traces left after past primary elements and their influence on current urban patterns and built forms for cities. In the case of the city of Lucca, we can still identify the urban footprint of an ancient amphitheatre and identify how it shaped current urban patterns and buildings. The same goes for the Piazza Navona in Rome, where an ancient Roman stadium has constituted the shape of the present large urban square fringed by building blocks.

Understanding how past policies and important buildings have constituted the development of a city requires insight into political, social, and technical changes that have occurred over time. Furthermore, how these changes had an influence on the built environment matters. Societal meanings and self-perceptions are closely intertwined with the built form (Lynch 1981), and the field of urban morphology is concerned with an understanding of the changes in the urban fabric over time (Strappa 2018; Panerai et al. 2004; Conzen 2004). Because this is always context dependent, it is difficult to derive a general statement about future effects when only taking the intrinsic properties of space into consideration.

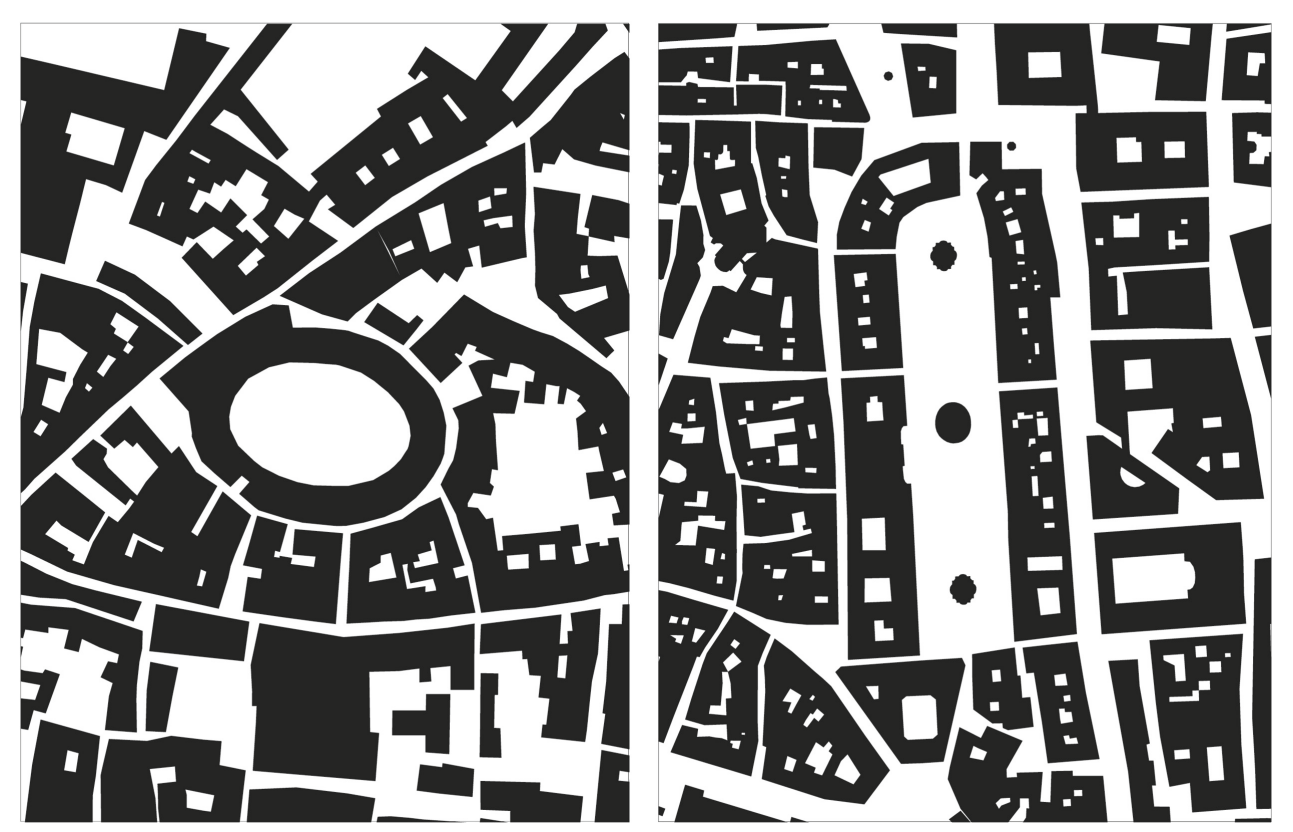

Fig. 1.16 An amphitheatre's influence on the urban pattern in the Italian town of Lucca (left), and an ancient Roman stadium's influence on Piazza Navona's built form in Rome (right) 
Because societal meaning and the self-perception of people are closely intertwined with the built form, we can conclude that every urban space has a place character. A place is a space with meaning. Place character and its identity are concerned with the intrinsic properties of space. Several factors influence place character, including location, topography, physical geography (e.g. a valley or hills), cultural traditions, local building materials, local weather conditions, demographics, and economics.

Norberg-Schulz describes the character-shaping elements of places. He takes into account how the assembly of local building materials, lighting, vegetation, landscape forms, weather conditions, and colours contribute to shaping the character of a particular place. The opening's shape, building materials, colours, rhythm, and tension determine the character. The meaning of the openings, such as doors, entrances, and windows, connects the private interior with the public space in terms of movement, light, and transparency. All these aspects express the way of life the city assembles. Every city has its local architectural motives (Norberg-Schulz 1971, p. 60).

Figure 1.17 shows three levels for understanding place character from the landscape level to the building level, and to the interior level for a Dutch and a Norwegian place. Seemingly, the building façade's orientation is influenced as a contrast to the natural landscape. Where a Norwegian landscape has a vertical orientation of the objects in the panoptical view, the structure of the traditional building façade's materials has a horizontal orientation. Conversely, the flat Dutch polder landscape has a horizontal orientation, which probably influences the vertical orientation of the shapes of windows and volumes of traditional Dutch buildings. The colours and textures of the interior are also influenced by local nature and weather conditions. The Norwegians like to bring the warm colours from the short Norwegian summer into the interior, whereas the Dutch use bright colours in their interiors for bringing light into their homes. 

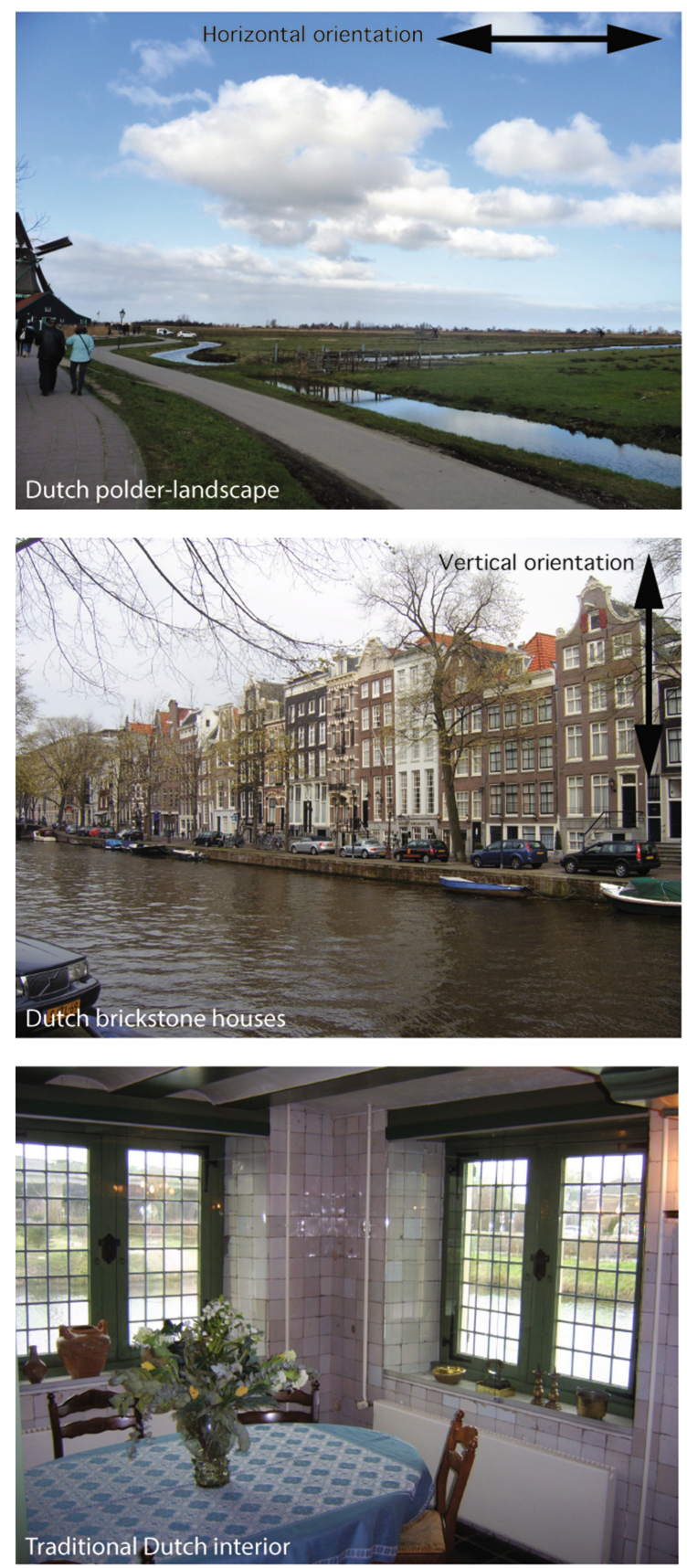

Landscape
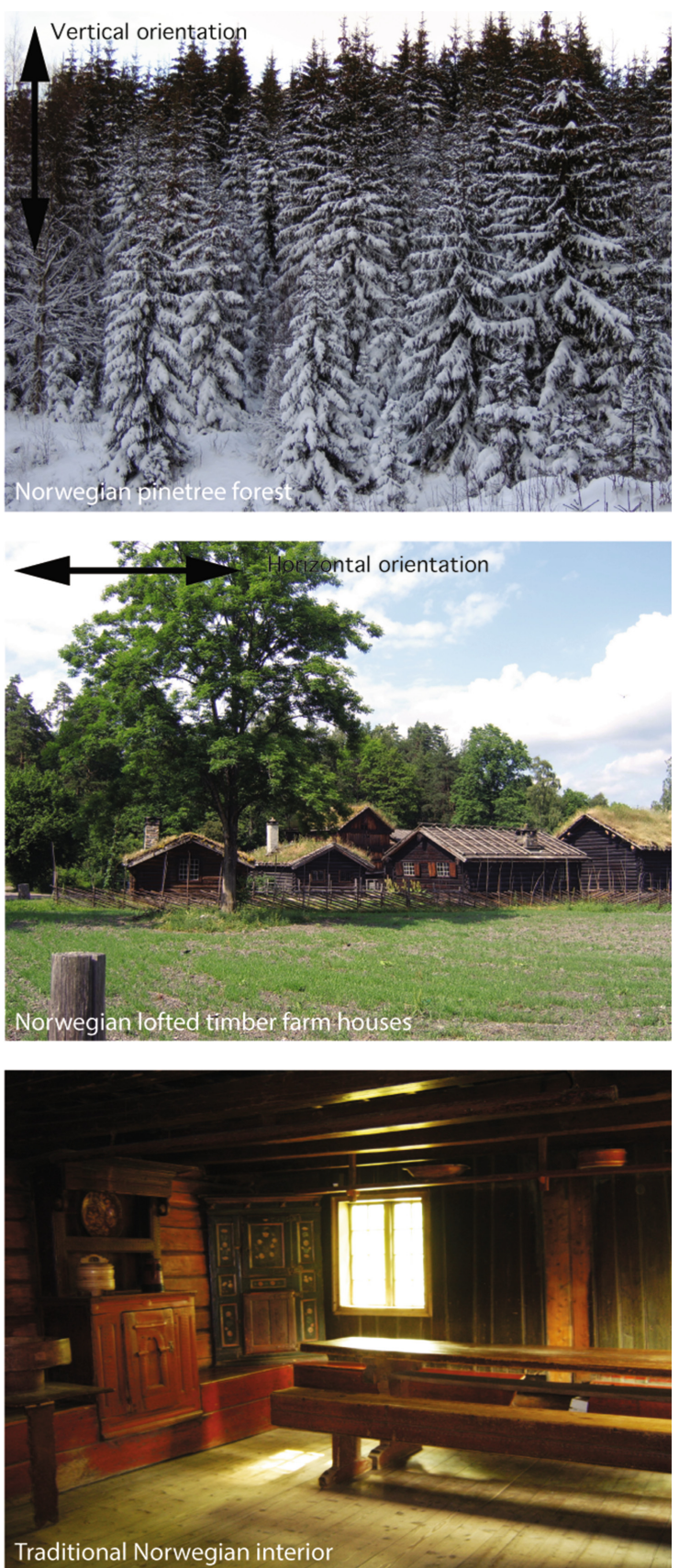

Fig. 1.17 Interpretation of Norberg-Schulz's approach to understanding the differences between a Dutch and a Norwegian place in the tradition of intrinsic properties of space

According to Norberg-Schulz, the experience of a place's character is spontaneously given in the way the direct feeling of being in a particular place offers us safety when we return home and excitement when we visit an unknown or new place. A place can be perceived as being friendly, cold, sombre, lively, enclosed, open, etc. The experience of a place's character creates the spirit of the place, the genius loci, and its inhabitants in the way it is expressed by the spatial structure and spatial elements. A vast space can never offer an intimate atmosphere, while a narrow space can never offer an atmosphere of openness and grandness. Every spatial structure can be organised in such a way that it conditions various character traits. Hence, the man-made built environment has a high degree of adjustability to the given natural surroundings. Urban place character depends on built boundaries and surfaces. It has a floor and walls. It is sometimes roofed. These elements influence 
how we experience urban place. Urban boundaries are not where a place stops, but where it begins, where its character is conditioned (Norberg-Schulz 1971).

For example, the rhythms of façades with their openings and windows express in cities a particular relationship between the inside and outside spaces. Different cities embrace very distinguished façades. Every place has its architectural theme driven by human motives and repeated with variations in a place's buildings. Thus, places are a combination of unity and variation. An urban theme consists of several motives; for example, a theme might be a certain type of façade with its particular windows (Norberg-Schulz 1971).

In general, urban morphology and place phenomenology in urban studies aim to understand the particular form and pattern of a city as an effect of processes. It is necessary to understand the intentions behind a built environment's artefacts and primary elements. With both the morphological and place phenomenological traditions, the future effects of new emerging and planned artefacts cannot be predicted. Analytical tools developed within these traditions are useful to understanding the existing/current relationship between built form and meaning.

Urban morphologists study the transformation rules guiding the change of urban patterns. They deal with type and typology and the classification of both based on common characteristics. The work of Rossi (1966, 1983), Muratori (1960), Caniggia (1976), Caniggia and Maffei (2001), Conzen (1960, 2004), Whitehand (1981), Panerai et al. (2004), Lynch (1960, 1981), and both Krier brothers (1984) are examples of applying intrinsic properties of space in urban studies. The work of these authors accounts for the built environment's observable characteristics, which refers to a built environment's phenotype, i.e. how the built objects in an urban space immediately appear to us.

Intrinsic properties of space are about built form and meaning, and describing and analysing a space's intrinsic properties require a place phenomenological approach. The meanings attached to single physical objects and the visible patterns these objects generate as a whole for a city combined with the atmosphere of the places need to be taken into account when trying to understand a particular built environment. Intrinsic properties of space describe the phenotypes of settlement patterns and the shape of their artefacts.

\subsubsection{Extrinsic Properties of Space}

The space syntax method works mainly with extrinsic properties, and it analyses the topological spatial relationships of settlements. It is difficult to describe the extrinsic properties of space with words. For example, if a visitor in a city asks an inhabitant the direction to the railway station, the inhabitant will use words like 'here', 'there', 'this way', and 'that way' to explain the route. Or the inhabitant will show the visitor the location of the railway station on a map.

Concepts like 'here' and 'there' or 'inside' and 'outside' are useful to refer to simple spatial relationships. But to describe an entire building or town using only the above-mentioned terms becomes very complicated. Language seems unable to spell out complex spatial relationships in a concise and simple manner. Therefore, abstract models or maps are often used to represent and grasp such complex systems of space. These models, which can represent large parts of our world, are necessary to explain spatial relationships.

During the development of space syntax, Hillier defined a number of basic terms for describing extrinsic properties in a systematic manner. This requires considering the city as a set of spaces. Wherever people move or live, their activities happen not just in a singular space, but also in multiple spaces. How these spaces are interrelated to each other influences the type of human activities (Hillier 1999).

In terms of how we name things, urban space is recognised to be mostly linear, perceived as a sequential constellation of spaces. Apart from squares, multiple names are used for the routes between squares such as alleys, streets, roads, avenues, boulevards, highways, paths, pavements, subways, bridges, and stairs. All these kinds of urban spaces shape a grid or network - a potential pattern of movement from everywhere to everywhere else. The way in which the square is used depends on where it is located in the linear mobility network. Therefore, urban space can be represented as linear items.

The urban street and road network is defined as the "pattern of public spaces linking the building of a settlement, regardless of its degree of geometric regularity" (Hillier 2001, p.02.1). The street network is the armature of a city and allows people to orientate and navigate through it. These urban public spaces give the possibility to move from everywhere to everywhere else in the city. The network of public spaces shapes the possibilities to spatially locate functions in response to the varying configurations of the urban street and road network. Space syntax works with the concepts of 'isovist field', 'convex space', and 'axial line' (Fig. 1.18). 
An isovist field is a visualisation of the panoptical view of a viewer from a particular standing point in the built environment (Bendikt 1979). Turner et al. (1993) argue that Tandy (1967) appears to have been the originator of the term 'isovist'. An isovist can be briefly explained as a visual record of what can be seen in a 360-degree view from a given point. The concept of an isovist is closely related to the idea of visual perception and spatial description, also connecting to Lynch's work. The visual record is taken at average eye height. Batty summarises an isovist as "[...] a field of vision from which various geometrical properties, such as area and perimeter, can be calculated. Isovists can be defined for every vantage point, constituting an environment, and the spatial union of any particular geometrical property defines a particular isovist field" (Batty 2001, p. 123). We will address the isovist analysis in depth in Chap. 3.

Moving on from this, a convex space is defined as a space used mostly for occupation, such that "all points (locations) within that space can be joined to all others without passing outside the boundary of that space. [...]" (Hillier 1988, p. 68). In other words, two persons can see each other when they are located on every spot within a particular convex space. The panoptical view is essential in the definition of a convex space. Convex space is mostly occupied by place-bound functions and human activities such as standing and sitting. In terms of spatial analysis, convex maps are used for analysing spaces inside buildings and the public spaces between groups of buildings in a neighbourhood or small village. The analytical scale ranges from architectural space to a neighbourhood's public realm.

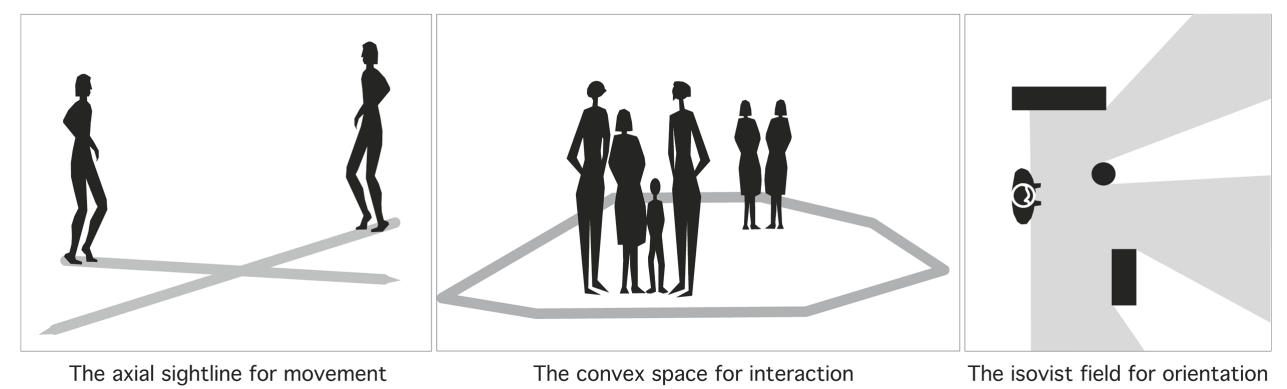

Fig. 1.18 An illustration of the basic elements of space syntax

The convex map is redeemed by the axial map simply because the axial map can be generated and drawn much faster than a convex map. Moreover, the analytical results of a convex analysis comply with those from an axial analysis (Hillier and Hanson 1984). For readers who are interested in learning more about convex spatial analyses, Chap. 3 in Hillier and Hanson's book The Social Logic of Space from 1984 offers insights into how to generate and analyse a convex map in the context of the French village of Gassin.

An axial map is the minimal set of axial lines, and an axial line represents the longest sightline distance for movement within a set of convex spaces. The axial line represents the way human beings move linearly through the urban street and road network. An axial line runs through a set of convex spaces that can be seen and passed through consecutively (Hillier and Hanson 1984, p. 94ff). In many ways, the axial line represents at the same time the movement line and the visual sightline. As Hillier and Hanson discovered in their studies on urban public space, the set of axial lines linking together convex spaces as 'beads on a string' can represent an urban network. The axial lines are the string (one-dimensional space representing the movement through built environments), and the convex spaces are the beads (2D space linked by one-dimensional space) (Hillier and Hanson 1984, p. 91).

For the analysis of towns and cities, the axial map is the least time consuming to prepare. For the axial map, the street and road network is represented with the longest and fewest sightlines indicating movement paths, presenting direction changes in terms of visibility. The most recently developed analytic techniques depart from the axial map as a basis, even though the use of the road centre line is becoming more popular for analysing large cities and regional areas. The axial map is a 
topological representation of the relationship of urban convex spaces and belongs to the representation of extrinsic properties.

Figure 1.19 illustrates the extrinsic properties of the spaces of town X. The left image depicts all publicly accessible spaces including all buildings. The right image represents the minimal set of axial lines for these spaces. This is coined the 'fewest-line axial map' (Turner et al. 1993, p. 425) because it illustrates the fewest and longest sightlines covering all public spaces in a built environment. The buildings' types and shapes do not matter. It is only their indoor spaces that are of interest if the axial analysis is applied to spatial relationships inside buildings.
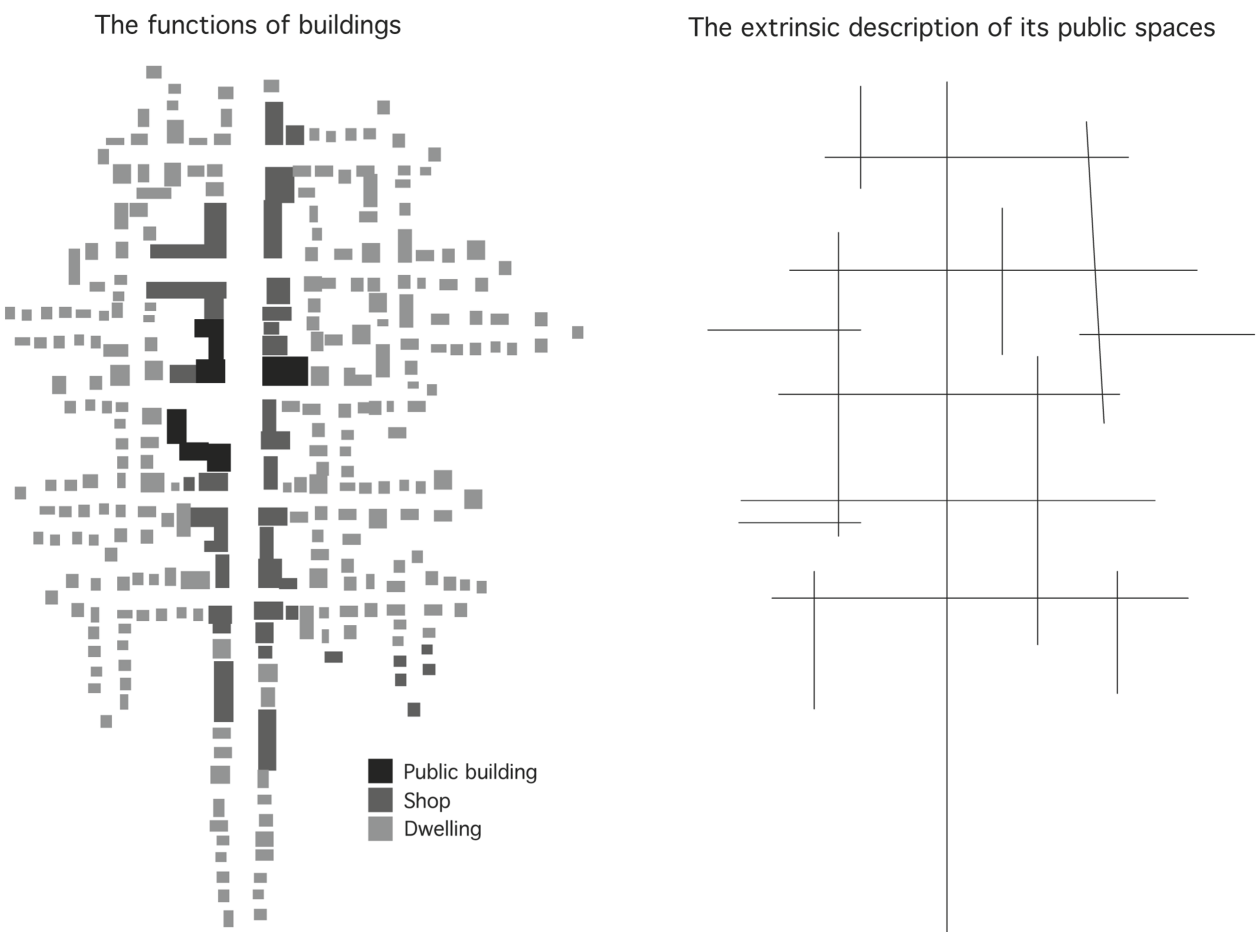

Fig. 1.19 How to represent a settlement's extrinsic properties of space

Describing extrinsic properties of space requires that urban elements of the complex urban reality can be represented in abstract models. Spatial models never cover the whole spectrum of urban reality due to their abstractive characteristic. They are a simplification of reality, and they cover what is of interest for the modeller and which urgent challenge should be addressed. As Joutsiniemi (2005, p. 360) says, "In the case of space syntax, the fewest and longest sightlines axial map is seen as a representation of publicly accessible spaces. It models or represented the required correspondence between world and model". In line with Turner et.al. (1993, p. 428), the objective way of modelling an axial map is to use the following rule of thumb: An axial map is the minimal set of axial lines such that the set taken together fully surveils the system.

Simplifying the extrinsic properties of the public spaces of the built environment in abstract units is needed in order to reveal their spatial interrelationships and to describe the spatial structure of these interrelationships. Figure 1.20 depicts a variety of basic spatial elements and presents them in their simplest diagrammatic form, followed by an axial representation and accordingly justified graphs. The root nodes are marked in black and represent the streets (a, b, c, and d) that are taken into consideration as a starting point.

The a-structure represents the tree-structured street network. The street with an a-structure is well connected and has high integration and high local choice of routes. However, this street has low traversability. The b-structure represents the street segment as part of a path. There are no side streets to the path. This linear structure therefore has low connectivity, has low integration values, and offers no local choices of other routes. The c-structure represents the street segment as part of a circular route. Like the path, the circle has low connectivity, low spatial integration, and low choices of other routes. However, the traversability of the circle is high. The d-structure represents the street segment as part of a network. Here the street segment is well connected, has high spatial integration, has high traversability, and offers a large number of choices of alternative routes (Hillier 2019). 
Fig. 1.20 Four types of elementary spatial relationships of public spaces
The street network

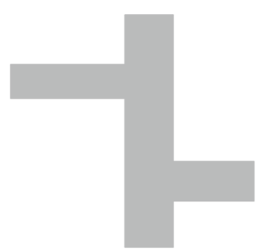

(a)

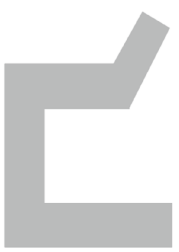

(b)

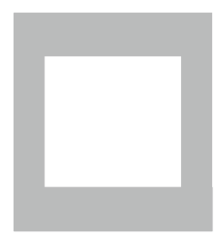

(c)

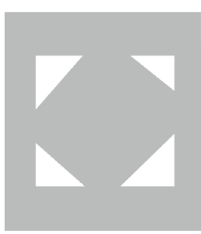

(d)
The axial representation

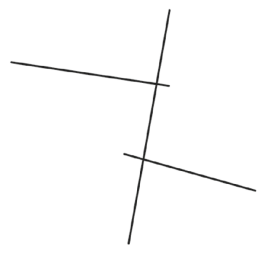

(a)

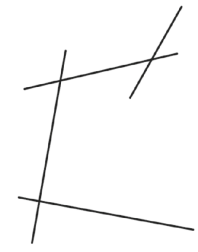

(b)

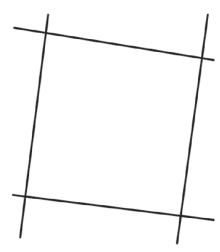

(c)

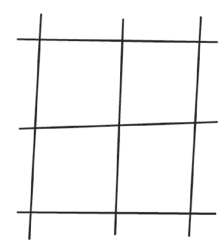

(d)
The justified graph representation

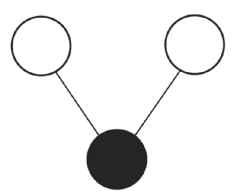

(a)

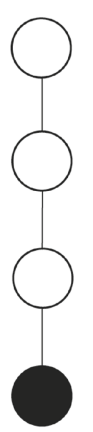

(b)
The star or the tree-structured street network

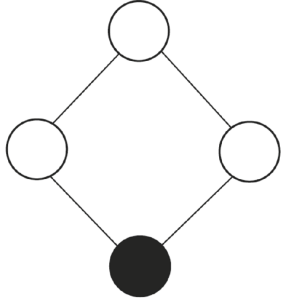

(c)

The path or the linear-structured street network
The cycle or the circular-structured street network

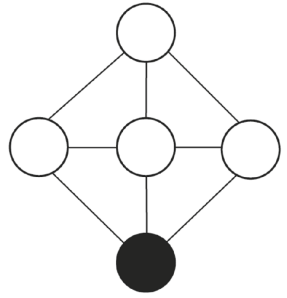

(d)

The wheel or the network-structured street network

Each of these elementary spatial relationships is a syntactic expression that is best expressed in relation to movement in public urban space. In spatial terms, the a-structure has a 0-directional movement. Here the key concept is stasis, which creates dead-end streets connected to the street. The stasis or star model is a non-distributed spatial system. The b-structure has a 1-directional movement, and the key concept is axis, which allows through movement but only the same way back. This axis is also a non-distributed spatial system. The c-structure has a 2-directional movement, and the key concept is route, which allows movements in two directions in a circle. Different from the first two, the c-structure is a distributed spatial system (Hillier and Hanson 1984, p. 91). Finally, the d-structure has a multi-directional movement, and the key concept is network, which offers several movement possibilities and many route choices. Clearly, the d-structure is a distributed spatial system. In social terms, the a-structure generates long models thus generating absence of movement, the b-structure distances long models, the c-structure accesses short models, and the d-structure generates short models (Hillier 2019). 
In summary, extrinsic properties of space are about the spatial relationships and the way these spatial relationships affect the location of various urban functions and the flow of human movement. The meaning of spaces, ergo places, is not considered in the analysis and description of the built environment in this context. Instead, the invisible spaces, shaped by objects and walls, and their interrelationship to each other are taken into account. Contrary to intrinsic properties, extrinsic properties of space are about identifying and describing a built environment's genotype - describing its hidden DNA or the spatial structure and underlying its spatial order.

\subsection{Conclusions}

Intrinsic properties of space are about describing patterns of built objects and place character. In the analysis of the arrangement of places, the work of urban morphologists like Muratori, Canaggia, Whitehand, Conzen, Panerai, and others supports the description of the spatial pattern of a place and relates it to socio-economic processes (Moudon 1997). Describing place character implies identifying the formal aspect of a built environment's spatial components. Our language is able to describe these elements and compare different settlements to one another. Moreover, these elements are also visible in the built environment.

Applying an extrinsic approach to describing a spatial structure is rather difficult. Herein, the spatial mathematical models are useful when describing spatial relationships. As David Seamon acknowledges, "Hillier and his colleagues have developed clearly defined concepts of space and spatial relationships for describing the hidden spatial structure determining a built environment's degree of liveliness and vitality" (Seamon 1994, p. 35-48). Space syntax is a configurative approach applying the logic of graph theory.

Urban spaces and places are shaped through social activities. Their spatial structures, arrangements, and orders influence human activities, perceptions, and existence. Movements in shaping cities have embraced diagrammatic, planned, and regular geometries representing normative approaches in contrast to the organic city or the city as an organism representing the evolved city. In general, it is hard to predict what urban planning and design interventions might mean for the everyday life of the users.

Urban change is refreshing for some people, while it is considered instability in their lives for others. Herein, space syntax as a spatio-social approach allows for testing the spatial-social effects of urban design proposals and for creating guidelines for generating places that function according to the plans' intentions by taking into consideration the spaces between the built objects. We have to focus on both urban space and urban form. Often the spatial structure shaped by the objects is forgotten when planning built environments even though urban space actively influences how human beings arrange their movements and functions. As shown in Chap. 6, urban form is influenced by urban space. Space syntax can analyse spatial structures, but not place character or building densities. Therefore, for a comprehensive analysis of the built environment, all three research traditions are needed.

Figure 1.21 shows the analysis of Oslo centre where we show one method of each of the three established research traditions on built environments. From the urban morphology tradition, we apply Rådberg's quantification of building morphology or the Spacematrix method (left). From the place phenomenology tradition, we apply Lynch's visual form map (middle), and from the urban network traditions we apply a space syntax analysis (right).

The Spacematrix approach and Lynch's visual form map both analyse the intrinsic properties of space. While the Spacematrix map depicts the urban pattern similar to a figure ground map, the visual form map allows one to learn about the visual quality and mental image of a city held by its residents. The visual form map further depicts the main phenotypes of a city's image appearing immediately before us.

Conversely, the space syntax analysis of the street network identifies the relationships of the public spaces to each other. Streets with a low number of direction changes (marked in red) in relation to all others have high spatial integration. These streets have high pedestrian flow rates and are often lively shopping streets. Conversely, streets with a high number of direction changes in relation to all others have low spatial integration and are marked in blue. These streets have potentially low pedestrian flow rates. This is an example of analysing extrinsic properties of space. Space syntax analysis depicts the built environment's 'hidden' spatial structure, aggregating various degrees of intensity of urban vitality, street life, and the location of active land use like shops and micro-economic businesses.

In which way built forms and functions are related depends on the spatial configurative relationship of the publicly accessible spaces represented by streets and squares. Some streets are spatially more highly integrated, and thus more 'central', while others are more spatially segregated. In general, active land use in the form of shops is located on spatially integrated main streets, while dwellings are located on spatially more segregated side streets. Thus, extrinsic properties of 

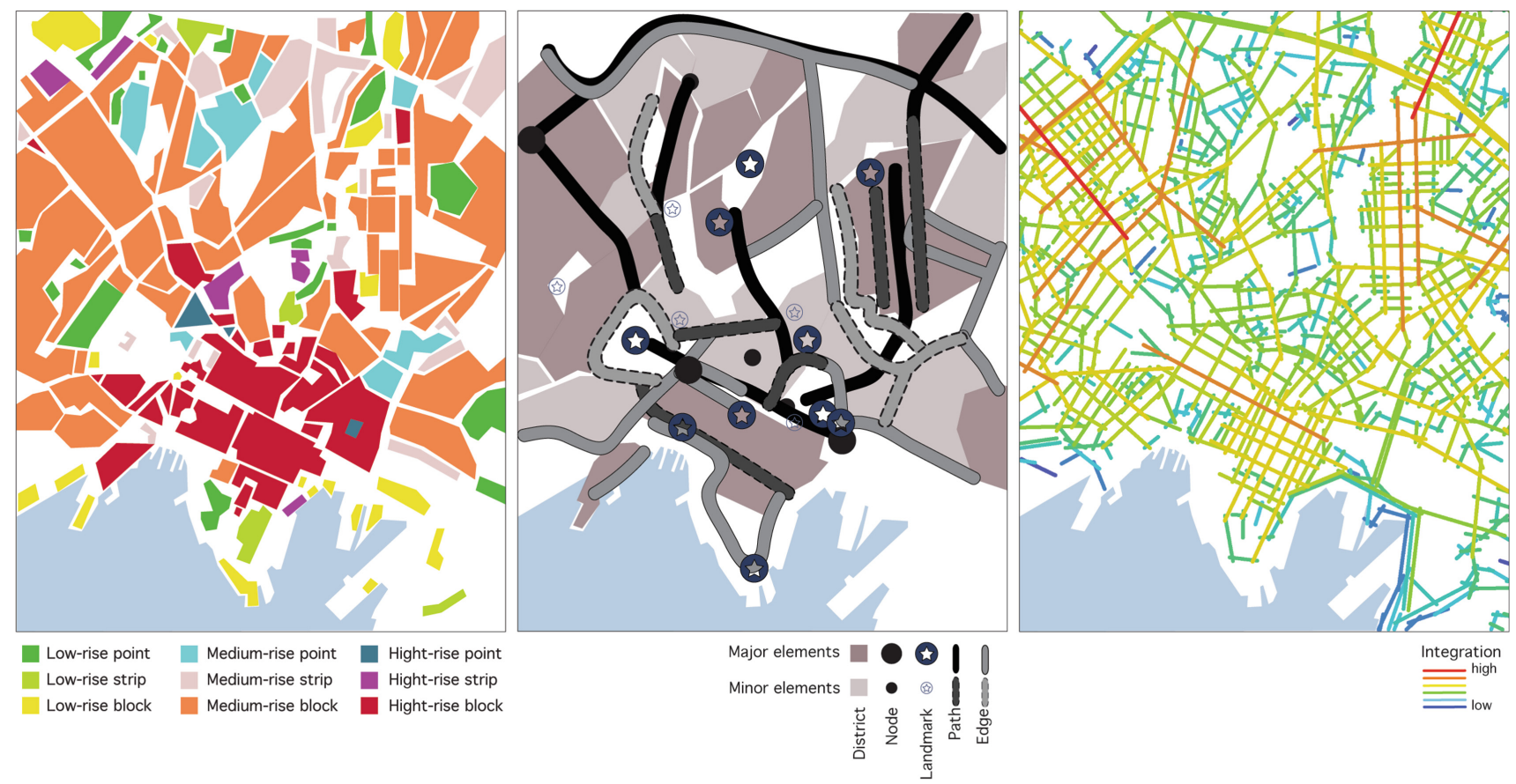

Fig. 1.21 Analysis of intrinsic and extrinsic properties for Oslo's historic centre from 2000: (left) Spacematrix analysis, (middle) visual form analysis, and (right) space syntax analysis of 'local integration'

space account for a settlement's genotype, which is its 'hidden' spatial structure of the public spaces shaped by buildings, land use demarcations, walls, and fences. These hidden spatial structures set the framework for what we can see, what we can access, and how we can move through and between all the physical obstacles placed in space.

In the following chapters, we will explain and demonstrate how the various spatial analysis methods are built up and the various calculation methods for space syntax. Examples from research and practice will be used. But before you go further, it is suggested to perform the exercises below.

\subsection{Exercises}

\section{Exercise 1}

Write a description of how you would explain to a stranger how to get from your home to the closest bus stop or railway station. Reflect upon what linguistic elements of your description refer to either extrinsic or intrinsic properties of space.

\section{Exercise 2}

Draw a Lynch-style visual form map of your home city, town, or village based on his five elements. Reflect upon the results: (a) Discuss the challenge in defining these elements for your case study. (b) Which of Lynch's five elements can be regarded as purely intrinsic? (c) Which of Lynch's elements can also show extrinsic properties of space?

\section{Exercise 3}

Draw a Spacematrix map of your home city, town, or village. You can use Google street maps' satellite images or Baidu Maps' satellites images (for those who cannot use Google) and street viewer as help. Try to classify the building types using the matrix of Fig. 1.3. 


\section{Exercise 4}

Undertake a manual MXI analysis of your home city, town, or village. Use Google street view or Baidu street view as an aid. Indicate with colours the location of the following areas: mono-functional dwelling areas, mono-functional work areas (business parks, industrial areas), mono-functional amenities (leisure activities), bi-functional areas with two functions, and multi-functional areas with all three functions.

\section{Exercise 5}

Undertake a comparative street function analysis of a historic neighbourhood and recent neighbourhood of a city or town you know well. Use Google or Baidu street view as an aid. Indicate with colours the following elements of the street network: pedestrian and bicycle streets; balanced use between vehicles, pedestrians, and bicycles; streets and roads dominated by vehicles; and roads only for vehicles. Describe the difference between both neighbourhoods based on your analysis. How do you experience both neighbourhoods?

\section{Exercise 6}

Get a map of your neighbourhood and highlight the distributed and non-distributed streets. How many circular routes can you identify in your neighbourhood? What is the percentage of $\mathrm{X}$ - and T-junctions in your neighbourhood?

\section{Exercise 7}

The image below illustrates a scouting camp within total eight tents. Out of the eight tents, there are five normal tents, one tent for the leader, one kitchen tent, and one bathroom tent. Each night the camp is installed in different places. Figure 1.22 shows three different camp configurations. Describe and explain the phenotype and genotype of these three different camp arrangements.

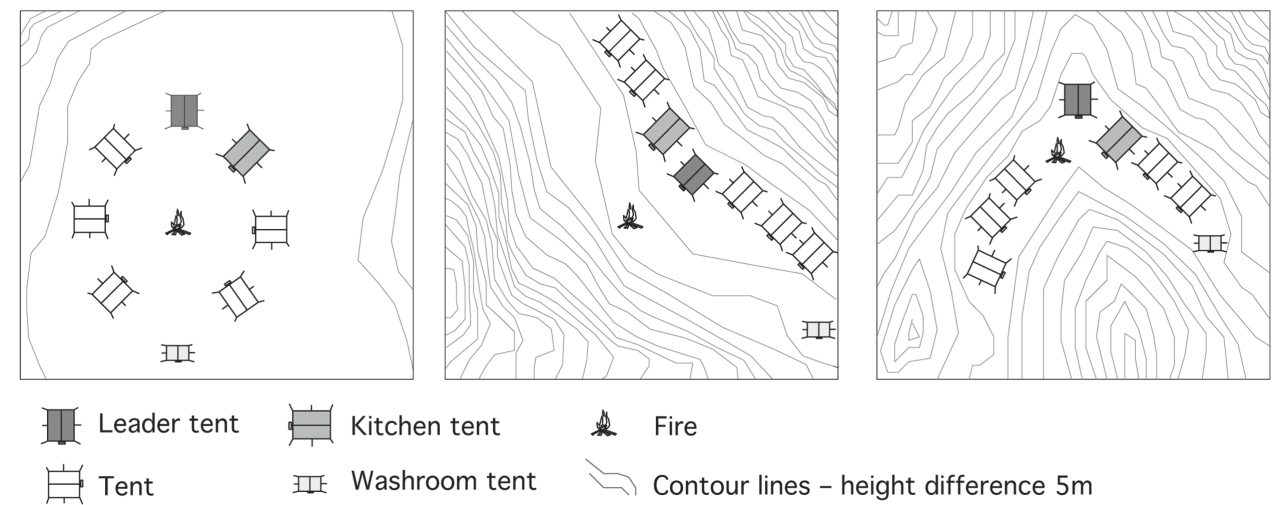

Fig. 1.22 Three different camp configurations

\subsection{Answers}

\section{Exercise 7}

The scouting camp's spatial organisation has the same genotype regards the location of the leader and kitchen tents in relation to the other tents and the bathroom tent. The phenotype of the scouting camp differs from each other, with a circle shape in the left figure, a linear shape in the middle figure, and a ' $\mathrm{V}$ ' shape in the right figure. 


\section{References}

Alexander, C. 1965. A city is not a tree. Architectural Forum 122(1 + 2): 58-62.

Alexander, C., S. Ishikawa, M. Silverstein, M. Jacobson, I. Fiksdahl-King, S. Angel. 1977. A pattern language. New York: Oxford University Press.

Batty, M. 2001. Exploring isovists fields: Space and shape in architectural urban morphology. Environment and Planning B 28: 123-150.

Batty, M. 2007. Cities and complexity: Understanding cities with cellular automata, agent-based models, and fractals. Massachusetts/London, England: MIT Press.

Batty, M. 2013. The new science of cities. Cambridge. Massachusetts/London, England: MIT Press.

Batty, M. 2018. Inventing future cities. Cambridge. Massachusetts/London, England: MIT Press.

Batty, M., and P. Longley. 1994. Fractal Cities: A geometry of form and function. Academic Press: London.

Benedikt, M.L. 1979. To take hold of space: Isovists and isovist fields. Environment and Planning B: Planning and Design 6: 47-65.

Berghauser Pont, M., and P. Haupt. 2010. Spacematrix —Space, Density and Urban Form. Ph.D. thesis. Delft University of Technology.

Caniggia, G. 1976. Strutture dello spazio antropico. Studi e note. Firenze: Uniedit.

Caniggia, G., and G.L. Maffei. 2001. Architectural composition and building typology: Interpreting basic building. Alinea Editrice: Florence.

Cataldi, G. 1991. Saverio Muratori: The thought and the work. Studie e documenti di architettura, nuova seria. ALINEA editrice srl.

Cataldi, G., G.L. Maffeiand and P. Vaccaro. 2002. Saverio Muratori and the Italian school of planning typology. Urban Morphology 6(1): 3-14.

Conzen, M.R.G. 1960. Alnwick, Northumberland: a study in town-plan analysis. Transactions and Papers. London: Institute of British Geographers. iii-122.

Conzen, M.P. 2018. Core concepts in town-plan analysis. In V. Oliveira (ed) Teaching urban morphology. Springer: Cham.

Conzen, M.R.G. 2004. Thinking about urban form: Papers on urban morphology, 1932-1998. Oxford: Peter Lang.

Corbusier, L. 1971. Towards a new architecture. London: Butterworth Architecture.

Cuthbert, A.R. 2007. Urban design: Requiem for an era-review and critique of the last 50 years. Urban Design International 12: 177-223.

Cuthbert, A.R. 2012. Understanding Cities: Method in urban design. London: Routledge.

Czerkauer-Yamu, C., and A. Voigt. 2011. Strategic planning with space syntax. In Proceedings in: eCAADe - 29th Conference in Education in Computer Aided Architectural Design in Europe, Ljubljana, pp. 125-133.

Dupuy, G. 2008. Urban networks—network urbanism. Delft: Techne Press.

Van Eldijk, J. 2014. Trygghetsutredning Noltorp. Göteborg: Rambøll.

Ellefsen, K.O., and D. Tvilde. 1990. Realistisk byanalyse. Trondheim: Arkitektavdelingen NTH.

Gabor, D. 1963. Inventing the future. London: Secker and Warbug.

Gehl, J. 1971. Livet mellem husene. Copenhagen: Arkitektens Forlag.

Gerosa, P.G. 1992. Éléments Pour une Histoire des Théories sur la Ville comme Artefact et Forme Spatiale. (XVIIIe - XXe siècles), vol. 7. Université des Sciences Humaines de Strasbourg, Collection Villes-Societés-Idées.

Haupt, P., and M. Berghauser Pont. 2004. Spacemate: The spatial logic of urban density. IOS Press. Delft University Press.

Hausleitner, B. 2010. Urban form and its impact on scope of action for people. Investigations on urban blocks in Paris. In: 17th conference International Seminar on Urban Form, ISUF 2010, Hamburg.

Heidegger, M. 1951. Bauen Wohnen Denken, Vortrag, gehalten am 5. August 1951 im Rahmen des "Darmstädter Gesprächs II" über "Mensch und Raum"; gedruckt in der Veröffentlichung dieses Gesprächs, Neue Darmstädter Verlagsanstalt 1952, S. $72 \mathrm{ff}$.

Hillier, B. 1988. Against enclosure. In Rehumanizing housing, N. Teymur, T. Markus, and T. Wooley (eds.). Butterworth: London, 63-88.

Hillier, B. 1996. Space is the machine: A configurational theory of architecture. Cambridge, UK: Cambridge University Press.

Hillier, B. 1999. Specifically architectural theory: A partial account of the ascent from building as cultural transmission to architecture as theoretical concretion. Bartlett School of Architecture. UCL.

Hillier, B. 2001. The theory of the city as object or how spatial laws mediate the social construction of urban space. In J. Peponis, J. Wineman, and S. Bafna, (eds.). Proceedings space syntax, 3rd international symposium. Atlanta.

Hillier, B. 2019. Structure or: Does space syntax need to radically extend its theory of spatial configuration. Keynote lecture presented by T. Yang 11. July 2019 at the 12th international space syntax symposium. Beijing: Beijing Jiao Tong University.

Hillier, B., and J. Hanson. 1984. The social logic of space. Cambridge, UK: Cambridge University Press.

Van der Hoek, J. 2010. The mixed use index (Mixed-use index) as planning tool for new towns in the 21st century. In New towns for the 21st century: The planned versus, the unplanned city, ed. M. Provoost, 198-207. Amsterdam: SUN Architecture.

Jacobs, J. 1960. The death and life of great American cities. New York: Random House.

Joutsiniemi, A. 2005. The ajax project: New theory and new software for space syntax. In A. van Nes, (ed.). Proceedings space syntax: 5th international symposium. Delft.

Karimi, K. 1998. Continuity and change in old cities; an analysis investigation of the spatial structure in Iranian and English historic cities before and after modernisation. Ph.D. thesis, The bartlett school of graduate studies, University College London.

Klaasen, I. T. 2004. Knowledge-based design: Developing urban \& regional design into a science. Ph.D. thesis, Delft University of Technology.

De Koning, R.E., A van Nes, Y. Ye and H.J. Roald. 2017. Strategies for integrated densification with urban qualities. Combining Space Syntax with building density, land usage, public transport and property rights in Bergen city. In T. Heitor, M. Serra, J.P. Silva, M.B. Carreira, L.C. Da Silva, E. Bazaraite (eds.). Proceedings of the 11th international space syntax symposium. Lisbon: University of Lisbon.

De Koning, R.E., and A. van Nes. 2019. Urban space and energy usage. In Qiang S. et al. (eds.). Proceedings of the 12th international space syntax symposium. Beijing: Beijing Jiao Tong University.

Krier, R. 1984. Urban space. London: Academy Editions.

Lynch, K. 1960. The image of the city. Cambridge, MA: MIT Press.

Lynch, K. 1981. A theory of good city form. Cambridge, Massachusetts/London, England: MIT Press.

Marzot, N. 2002. The study of urban form in Italy. Urban Morphology, 6(2).

Marshall, S. 2005. Streets and patterns. Oxon: Spon Press. 
Meinert, M., S.T. Thomassen, A. van Nes, H.J. Roald, and T.L. Skovsgaard. 2019. How children use urban space in two different neighbourhoods in Bergen, Norway. In Qiang S et al. (eds.). Proceedings of the 12th international space syntax symposium. Beijing: Beijing Jiao Tong University.

Moudon, A.V. 1997. Urban morphology as an emerging interdisciplinary field. Urban Morphology 1: 3-10.

Muratori, S. 1960. Studi per una operante storia urbana di Venezia. 2nd edn. Istituto Poligrafico dello Stato. Roma.

Van Nes, A. 2002. Road building and urban change: The effect of ring roads on the dispersal of functions in Western European towns and cities. Ph.D. thesis, Agricultural University of Norway.

Van Nes, A. 2017. What is the explanatory power of space syntax theory? The application of modal logics from theory of science. In T. Heitor, M. Serra, J.P. Silva, M.B. Carreira, L.C. Da Silva, E. Bazaraite (eds.). Proceedings of the 11th international space syntax symposium. Lisbon: University of Lisbon.

Van Nes, A., M. Berghauser Pont, and B. Mashhoodi. 2012. Combination of space syntax with spacematrix and the mixed use index: The rotterdam south test case. In Proceedings of the 8th international space syntax symposium. Santiago de Chile: PUC.

Van Nes A., and C. Yamu 2020. Exploring challenges in space syntax theory building: the use of positivist and hermeneuticexplanatory models, sustainability, 12(17), 7133. https://doi.org/10.3390/su12177133

Norberg-Schulz, C. 1971. Mellom jord og himmel. En bok om steder og hus. Universitetsforlaget, Oslo.

Norberg-Schulz, C. 1980. Genius loci. Rizzoli International Publications INC, New York.

Oliveira, V. 2018. Teaching urban morphology. Cham: Springer.

Oliveira, V. 2019. JWR Whitehand and the historico-geographical approach to urban morphology. Cham: Springer.

Panerai, P., J. Castex, J.C. Depaule, and I. Samuels. 2004. Urban forms - the death and life of the urban block. Architectural Press, London.

Popper, K.R. 1963. Conjectures and refutations: The growth of scientific knowledge. London: Routledge \& Keagan. Paul Limited.

Ratti, C. 2004. Space syntax: Some inconsistencies. Environment and Planning B: Planning and Design 31 (4): 487-499.

Rossi, A. 1966. L'architettura della citta. Padua, Italy: Marsilio Press.

Rossi, A. 1983. The architecture of the city. Cambridge, Massachusetts: MIT Press.

Rådberg, J. 1996. Towards a theory of sustainability and urban quality; A new method for typological urban classification. In Gray, M. (ed.). 14th conference of the international association for people-environment studies. Stockholm, 384-392

Seamon, D. 1994. The life of the place. Nordisk Arkitekturforskning. 1: 35-48.

Shu, C.F. 2000. Housing layout and crime vulnerability. Ph.D. thesis, The Bartlett School of Graduate studies, University College London.

Strappa, G. 2014. L'architettura come processo. Milan: FrancoAngeli.

Strappa, G. 2018. Reading the built environment as a design method. In Oliveira V. (ed.). Teaching urban morphology. Springer: Cham.

Ståhle, A., L. Marcus, A. Karlström. 2005. Place Syntax-Geographic accessibility with axial lines in GIS. In: A. van Nes. (ed.). Proceedings 5th international space syntax symposium. TU Delft. Techne Press. Amsterdam.

Tandy, C.R.V. 1967. The isovist method of landscape survey. In Symposium: Methods of landscape. Analysis H.C. Murray (ed.). (Landscape Research Group, London) 9-10.

Thiis-Evensen, T. 1987. Archetypes in architecture. Oxford University Press.

Thiis-Evensen, T. 1992. Archetypes in Urbanism. Aschehoug.

Troye, S.V. 1994. Teori og forskningsevaluering: Et kritisk realistisk perspektiv. Tano, Oslo.

Turner, A., A. Penn, and B. Hillier. 1993. An algorithmic definition of the axial map. Environment and Planning B: Planning and Design 32: 425444.

Vagstein, A.M. 1999. Stedet og det Stemte Rom. Sammenheng mellom Sted og Arkitektur. Ph.D. thesis, Oslo School of Architecture.

Van Wegen, H., and D. van der Voort. 1991. Sociale veiligheit en gebouwde omgeving. Ph.D. thesis, Technische Universiteit Delft.

Whitehand, J.W.R. (ed.). The urban landscape: Historical development and management papers by M. R. G. Conzen Institute of British Geographers Special Publication 13. Academic Press.

Whitehand, J.W.R. 2018. Crossing boundaries: Towards a more integrated approach? Urban Morphology 22: 99-100.

Yamu, C. 2014. It is simply complex(ity). Modeling and simulation in the light of decision-making, emergent structures and a world of non-linearity. disP-The Planning Review, 50(4): 43-53.

Yamu, C., G. de Roo, and P. Frankhausen. 2016. Assuming it is all about conditions. Framing a simulation model for complex, adaptive urban space. Environment and Planning B. 43(6): 1019-1039.

Yamu, C., and A. van Nes. 2017. An integrated modeling approach. combining multifractal urban planning with a space syntax perspective. In Urban Science 1(37). https://doi.org/10.3390/urbansci1040037

Yamu C, A. van Nes, and C. Garau. 2021. Bill Hillier's legacy: Space syntax — a synposis of basic concepts, measures, andempirical application, sustainability, 13(6): 3394. https://doi.org/10.3390/su13063394

Ye, Y., and A. van Nes. 2013. Measuring urban maturation processes in Dutch and Chinese new towns: Combining street network configuration with building density and degree of land use diversification through GIS. In Journal of Space Syntax, Special Issue, Urban Challenges. Space and society in the contemporary urban world.

Ye, Y., and A. van Nes. 2014. Quantitative tools in urban morphology: Combining space syntax, spacematrix and mixed-use index in a GIS framework. Urban Morphology 18 (2): 97-118.

\section{Further Readings}

Carmona, M., T. Heath, T. Oc, and S. Tiesdel. 2012. Public places-Urban spaces: Routledge.

Gehl, J. 1987. Life between buildings. London: Island Press.

LeGates, R.T., and F. Stout. 2011. The city reader. 5th edn. Routledge Urban Reader series.

Norberg-Schulz, C. 1980. Genius loci. New York: Rizzoli International Publications INC. 
Van Nes, A. 2012. Between heaven and earth. Christian Norberg-Schulz's contribution to the phenomenology of place and architecture. In Environmental and architectural phenomenology, Vol. 23, No. 1, winter.

Yamu C, A. van Nes, and C. Garau. 2021. Bill Hillier's legacy: Space syntax — a synposis of basic concepts, measures, andempirical application, sustainability, 13(6): 3394. https://doi.org/10.3390/su13063394

Open Access This chapter is distributed under the terms of the Creative Commons Attribution 4.0 International License (http://creativecommons. org/licenses/by/4.0/), which permits use, duplication, adaptation, distribution and reproduction in any medium or format, as long as you give appropriate credit to the original author(s) and the source, a link is provided to the Creative Commons license and any changes made are indicated.

The images or other third party material in this chapter are included in the work's Creative Commons license, unless indicated otherwise in the credit line; if such material is not included in the work's Creative Commons license and the respective action is not permitted by statutory regulation, users will need to obtain permission from the license holder to duplicate, adapt or reproduce the material. 